\title{
Viejo y nuevo pragmatismo
}

\author{
SUSAN HAACK \\ Department of Philosophy \\ University of Miami \\ s.haack@miami.edu
}

\begin{abstract}
RESUMEN: C.S. Peirce, fundador del pragmatismo, propuso una filosofía científica reformada que se rige por la máxima pragmática, que asocia el significado de un concepto con sus consecuencias experienciales. Sin embargo, con el tiempo, el pragmatismo evolucionó: de la articulación lógica, idealista-realista de Peirce, pasó por el pragmatismo más psicológico y nominalista de James, hasta llegar en nuestros días a Richard Rorty, quien propone, en nombre del pragmatismo, que el territorio metafísico y epistemológico que forma el centro tradicional de la filosofía se abandone, y que la filosofía se convierta en un género de literatura; mientras que, en el otro extremo, filósofos científicos como Paul Churchland y Stephen Stich también se describen a sí mismos como pragmatistas. Revisando la historia del pragmatismo desde Pierce y James, pasando por Dewey, Mead y Schiller hasta nuestros días, este artículo detalla la transmutación del viejo pragmatismo en el nuevo.
\end{abstract}

Palabras ClaVE: pragmatismo, C.S. Peirce, Richard Rorty, verdad, William James

\begin{abstract}
"Probablemente nunca ha sucedido que un filósofo haya intentado darle un nombre general a su propia doctrina, sin que ese nombre adquiera pronto, en el uso filosófico general, un significado mucho más amplio que el que originalmente se pretendió. .. " [C.S. Peirce, CP, 5.412]

"Jamás hubo confusión mayor. La Torre de Babel resulta monótona en comparación [...] Dewey es oscuro; Schiller, pomposo y atolondrado; la doctrina del empirismo radical de James [. . . ] ha sido confundida con el pragmatismo; el pragmatismo mismo abarca dos o tres teorías distintas [...] el resultado ha sumido la inteligencia humana en la desesperación. Pero poco a poco el limo se posará en el fondo..." [William James, 1907a, p. 134]
\end{abstract}

Fue William James quien acuñó la palabra "pragmatismo" como término filosófico y lo hizo famoso; pero reconoció que Pierce lo había introducido por primera vez durante las disertaciones que dio a principios del decenio de 1870 en el "Club Metafísico" de Cambridge, Massachusetts. De hecho, el espíritu del pragmatismo ya permea los notables escritos anticartesianos que Peirce publicó entre 1868 y 1869, así como "How to Make Our Ideas Clear" (1878). 
Más adelante, Peirce escribió que había tenido sus reservas para introducir el término "pragmatismo" con un significado filosófico especial, pues temía que se lo confundiera con su uso común, no filosófico. Pero había acabado por pensar que esto había sido un error, que los filósofos no sólo pueden, sino que deben adaptar palabras corrientes a nuevos significados, o introducir palabras nuevas, según lo exija la claridad. Resulta irónico, pues, que haya existido la tendencia, cada vez más marcada con el transcurso del tiempo, de confundir el sentido filosófico especial que Peirce dio al término pragmatismo con su sentido más común, de preocupación por la diligencia más que por el principio.

Lo que Peirce proponía era una filosofía científica reformada, guiada por la máxima pragmática que identifica el significado de un concepto con las consecuencias que éste tiene "para una conducta deliberada, controlada por uno mismo [...] de afirmación o negación del concepto" (1904, p. 56). Aunque emparentado, en líneas generales, con el positivismo, el pragmatismo de Peirce no era antimetafísico. Pues, al contrario del positivismo más estrecho de Augusto Comte, "en vez de limitarse a burlarse de la metafísica, [el pragmatismo] extrae de ella una valiosa esencia" (5.423), sustituyendo el viejo y fallido enfoque apriorístico por una metafísica científica reformada.

La filosofía reformada que Peirce visualizaba sería abordada con una "actitud científica", a partir de un deseo genuino de descubrir la verdad, lo que "es Así, independientemente de lo que usted, yo o cualquiera crea que es o no de ese modo" (2.135); y utilizaría "los métodos más racionales que puedan concebirse para descubrir lo poco que falte aún por ser descubierto sobre el universo de la mente y la materia, a partir de esas observaciones que toda persona puede hacer en cualquier momento de su vida de vigilia" (1.126). Sin embargo, aunque rescataría "el sólido barco Filosofía de las manos de los desenfrenados corsarios que surcan el mar de la literatura para ponerlo al servicio de la Ciencia" (5.449), el pragmatismo de Peirce no era cientificista; no delegaría las cuestiones filosóficas a las ciencias naturales para que éstas las respondieran, ni las desplazaría a favor de interrogantes científico naturales.

No obstante, por alguna razón el pragmatismo reformista clásico se transformó gradualmente en un neopragmatismo revolucionario, y la aspiración de Peirce de reformar la filosofía volviéndola más científica derivó poco a poco en un cientificismo a ultranza, por un lado, y en un etéreo diletantismo literario, por el otro. Estos dos estilos neopragmáticos, aparentemente contradictorios, tienen esto en común: cada uno, a su propia manera, repudiando los proyectos filosóficos tradicionales, se encuentra más cercano al estilo furiosamente antifilosófico del positivismo que al pragmatismo clá- 
sico. Ambos son más revolucionarios que reformistas, y ambos presentan una tendencia más o menos abiertamente antiintelectual.

Richard Rorty, el neopragmatista contemporáneo más influyente, propone, en nombre del pragmatismo, que se abandone y se deje desocupado el territorio metafísico y epistemológico que formaba el centro tradicional de la filosofía; que se deje de lado la vieja preocupación por el método y el argumento, admitiendo que "conocer nuestros deseos es conocer el criterio de la verdad" (1991a, p. 31) y que llamar verdadero a un enunciado no es sino darle "una retórica palmadita en la espalda" (1982, p. xvii); y que la filosofía debe disociarse de la ciencia para reconstituirse como un género literario "al servicio de la política democrática" (1989, p. 196).

Y actualmente los filósofos de la más atrevida estirpe científica también se consideran pragmatistas: Paul Churchland, por ejemplo, quien nos dice que, como la incesante actividad cognitiva de los ganglios de los nudibranquiados no entrañan representaciones, deberíamos abandonar la idea de que la verdad es el objetivo de la investigación (1989, pp. 150-151); y Stephen Stich, quien nos asegura que "una vez que tengamos una visión clara de la materia", advertiremos que poseer creencias verdaderas carece de valor (1990, p. 101).

En suma, la historia del pragmatismo es a la vez confusa y perturbadora. Confusa porque, a medida que las concepciones filosóficas sustanciales y las concepciones de la filosofía presentadas bajo la rúbrica del "pragmatismo" proliferan con una variedad desconcertante, uno comienza a preguntarse si el nombre sirve a algún propósito real. Perturbadora porque, en tanto las aspiraciones reformistas de la tradición pragmática clásica han sido transformadas por los neopragmatistas contemporáneos en una u otra forma de antiintelectualismo revolucionario, uno comienza a temer que Russell tuviera razón cuando predijo que el pragmatismo conduciría a la "impiedad cósmica" o, en todo caso, al fascismo.

Hace mucho, A.O. Lovejoy se quejó de que había trece pragmatismos; Ralph Barton Perry sugirió que el pragmatismo era resultado de la malinterpretación que James hizo de Peirce; el pragmatista británico F.C.S. Schiller reconoció despreocupadamente que había tantos pragmatismos como pragmatistas. Más recientemente, Rorty escribió que “'pragmatismo' es un término vago, ambiguo y sobrecargado" (1982, p. 160), mientras Mounce argumentó que hay dos pragmatismos: el honorable, que desciende de Peirce, y el deshonroso, que va de James y Dewey a Rorty et al. Cada uno tiene cierta razón, pero el problema es en realidad más complejo e interesante de lo que ninguno de ellos admite, y se parece más al viejo chiste de los soldados que pasan un mensaje a lo largo de la fila: el primero le dice 
al segundo, "Envíen refuerzos, vamos a avanzar"; y el penúltimo le dice al último, "Envíen dinero, vamos a bailar".

Charles Sanders Peirce (1839-1914), hijo del distinguido matemático de Harvard Benjamin Peirce, estudió química y trabajó como científico, además de ser el más grande de los filósofos estadounidenses. De 1879 a 1884 dio clases en la Universidad Johns Hopkins; entre sus estudiantes estuvieron Christine Ladd (más adelante Ladd-Franklin), O.H. Mitchell, Josiah Royce, Thorstein Veblen y John Dewey, aunque Dewey decidió no tomar su clase de lógica: "el curso es muy matemático, y por Lógica, el señor Peirce sólo entiende una relación de los métodos de la ciencia, expresados en la forma más matemática posible" (tomado de Dykhuizen 1973, pp. 30-31). En 1887, cuando recibió una modesta herencia, Peirce se retiró a Milford, Pensilvania, donde pasó el resto de su vida casi aislado, escribiendo abundantemente sobre temas filosóficos y científicos.

Primero en describirse a sí mismo como lógico en Who's Who, Peirce consideraba el pragmatismo "principio y método del razonamiento correcto". La máxima pragmática sirve tanto para explicar el significado de conceptos difíciles como para poner al descubierto la falta de sentido de algunas polémicas metafísicas. Para poseer un concepto en el primer grado de claridad sólo se requiere de la capacidad para usar un término; para poseerlo en el segundo grado, únicamente la capacidad para dar una definición verbal. Sin embargo, para poseer un concepto en el tercer grado de claridad se necesita comprender su significado pragmático — "pragmático" en el sentido kantiano de pragmatisch, experiencial. "Si uno es capaz de definir con precisión todos los fenómenos experimentales concebibles que la afirmación o la negación de un concepto pueda implicar, tendrá una definición completa del concepto, y no habrá absolutamente nada más en él" (5.142).

El significado pragmático de un predicado está dado por una lista de condicionales, al efecto de que el predicado se aplica sólo en caso de que, si tal y cual tipo de acción se lleva a cabo, se obtendrán tales y cuales consecuencias experienciales. O más bien, como insiste el Peirce de la madurez que ha superado sus juveniles inclinaciones nominalistas, la formulación sería subjuntiva: "si se hiciera A1, se seguiría la consecuencia experiencial E1", "si se hiciera A2, se seguiría la consecuencia experiencial E2",..., etc. Pierce critica sus escritos de juventud por haber sugerido que es indiferente si decimos que un diamante que nunca ha sido frotado es duro o que no lo es; un diamante es realmente duro si raspara otras sustancias si fuera frotado contra éstas.

La lista de condicionales que especifican el significado es abierta, pues el significado aumenta a medida que se acrecienta nuestro conocimiento. 
"Cuánto más significa la palabra electricidad hoy en día que en la época de Franklin", observa Peirce; "cuánto más significa actualmente el término planeta que en los tiempos de Hiparco. Estas palabras han adquirido información" (7.587).

Peirce considera la metafísica "el París del intelecto", excitante pero peligrosa, pues, según los criterios de la máxima pragmática, casi toda proposición de la metafísica ontológica [...] es un galimatías" (5.423). Pero una vez que esta basura sin sentido ha sido eliminada, puede comenzar el verdadero trabajo de la metafísica científica, emprendido con una actitud científica y usando el método de la ciencia.

Por "actitud científica", Peirce entiende un deseo genuino de descubrir cómo son las cosas. Cree que, cuando ha caído en manos de los teólogos, la filosofía se ha limitado muy frecuentemente a falsos razonamientos, argumentos dolosos a favor de una doctrina ya inamoviblemente sostenida; y cuando ha caído en manos de esos anárquicos tipos literarios, no ha sido por lo general más que un simple diletantismo, motivado por el deseo de escribir un documento agradable, "un auténtico libertinaje del pensamiento" (5.396). Para que progrese, la filosofía debe ser abordada con el espíritu de buscar la verdad, el mismo que ha inspirado a las ciencias naturales; debe ser una investigación genuina, de buena fe.

Por "método de la ciencia", Peirce entiende el método de la experiencia y el razonamiento, el que ha permitido los logros de las ciencias naturales y el que la filosofía debería adoptar. Pero mientras que las ciencias naturales se basan en tipos especializados y rebuscados de experiencias, que sólo pueden obtenerse por medio de instrumentos, la filosofía científica debe basarse en aspectos de la experiencia que sean tan familiares y ubicuos que la dificultad consiste en tomar clara conciencia de ellos. De aquí el interés de Peirce por la fenomenología o, como él la llama, "faneroscopía".

Puede reconocerse el carácter científico, en este sentido muy amplio, de la manera en que Peirce aborda las cuestiones metafísicas tradicionales. Defiende sus categorías (primeridad, es decir, la cualidad, la potencialidad; segundidad, a saber, la existencia particular, la reacción, y terceridad, la generalidad, la conexión, la ley) no sólo desde la perspectiva de su lógica de los emparentamientos, sino también fenomenológicamente. Su explicación de la percepción, inspirada en sus categorías, también posee un fundamento fenomenológico. Otras hipótesis de la metafísica científica de Peirce son el tiquismo (hay una indeterminación objetiva, además de ley, en el universo); sinequismo (la ubicuidad de la continuidad); el agapismo (la evolución gradual del mundo del caos al orden); el realismo escolástico (hay generalidades verdaderas). 
La concepción de Peirce de una filosofía científica reformada ya está operando en sus primeros escritos, en los que ofrece una detallada crítica de la epistemología cartesiana y comienza a desarrollar su propia teoría de la investigación, cautivantemente naturalista. Con Descartes, la filosofía "dejó de lado las puerilidades y empezó a ser un joven vanidoso" (4.71). El método de Descartes es un galimatías, que requiere de fingidas dudas "de papel". No existe una facultad como la intuición, que presupone el criterio de la claridad y la distinción de Descartes, ni una conciencia intuitiva de sí mismo, como exige su confianza en el cogito en tanto punto de partida indudable para la reconstrucción del conocimiento. La aspiración de Descartes a la certidumbre está desubicada, y su subjetivo criterio de verdad es viciosamente individualista.

En oposición a Descartes y con un espíritu sorprendentemente darwiniano, Peirce concibe la investigación como una continuación de las exploraciones que los animales hacen de su ambiente. Siguiendo a Alexander Bain, entiende la creencia como algo que implica hábitos de acción y la duda como el estado inestable que resulta de la interrupción de un hábito de creencia debida a una obstinación por parte de la experiencia. Esta duda real y viviente, al contrario de la duda de papel cartesiana, es por lo tanto involuntaria y desagradable. La primitiva base de la actividad cognitiva más compleja del ser humano es un proceso homeostático en el cual el organismo lucha por recuperar el equilibrio, proceso que comienza con una duda y finaliza cuando se llega a un nuevo hábito, a una creencia revisada.

Peirce compara cuatro métodos para fijar la creencia. El método de la tenacidad no es más que aferrarse obstinadamente a las creencias que uno tiene, cualesquiera que sean, evitando toda evidencia que pueda desequilibrarlas. El método de la autoridad consiste en someterse a una Iglesia o a un Estado que imponen la conformidad a la creencia. El método apriorístico, favorecido tradicionalmente por los metafísicos, busca fijar la creencia investigando lo que es "agradable a la razón". Pero los investigadores más refinados, que aspiran a una creencia irrevocablemente establecida, siempre estarán motivados a continuar las investigaciones, sin sentirse jamás plenamente satisfechos con lo que se inclinan a pensar en el presente. Así, la culminación de ese primitivo proceso homeostático es el método científico, el único método, argumenta Peirce, que con el tiempo producirá creencias irrevocablemente estables, a salvo para siempre de la obstinación.

Si realmente se quiere conocer la verdad, hay que admitir que lo que uno sabe todavía no es satisfactorio; de este modo, el investigador científico es un "falibilista contrito" (1.14), dispuesto a "abandonar toda su carga de creencias en cuanto la experiencia se les oponga" (1.55). Desde la perspectiva del sentido común crítico de la filosofía madura de Peirce 
- un intento de síntesis, como lo indica la frase, de las respuestas de Kant y Reid a Hume-, el investigador científico es visualizado como alguien que somete las creencias instintivas del sentido común a la crítica, la afinación y la revisión.

En consecuencia, habrá un refinado tipo de "vacilación fingida": la duda científica que (si bien no será la duda cartesiana general) no necesita ser provocada directamente por una obstinación por parte de la experiencia. La duda científica puede ser cultivada deliberadamente y "no descansará nunca por completo hasta que, por fin, se establezca la verdad misma de lo que está en cuestión" (7.77).

En la filosofía de Peirce, el individuo aparece como locus de la ignorancia y el error, y como alguien que sólo toma conciencia de sí mismo a medida que interactúa con otros. De este modo, como cabe esperar, la concepción peirceana de la investigación científica no es sólo completamente falibilista, sino también completamente social. Cada investigador genuino y de buena fe contribuye a una vasta empresa en su época y a lo largo de las generaciones al poner su obra gratuitamente a disposición de otros; así, aunque fracase, los suyos serán parte de los restos sobre los que treparán las futuras generaciones de investigadores para asaltar la fortaleza del conocimiento.

Por falible e imperfecta que sea la investigación científica, si continuara el tiempo suficiente - Pierce es consciente de que no hay garantías de que lo haga - se acordaría finalmente una opinión última, irrevocablemente establecida. ¿Por qué? Los elementos clave son la combinación de lo directo y lo interpretativo en la teoría peirceana de la percepción, la doctrina metafísica que él llama "realismo escolástico" y su concepción del razonamiento implicado en la investigación científica.

La concepción peirceana de la experiencia es amplia e incluye a la vez la percepción sensorial y, en matemática, la observación de diagramas imaginarios. La percepción sensorial, según Peirce, es tanto directa como interpretativa. El perceptum, para usar el término que acuñó en 1902, consiste en el percepto, el hecho perceptual o presentación, y el juicio perceptual, la creencia provocada por la experiencia; ambos son conceptualmente distintos, aunque por lo general inseparables en la práctica.

Un percepto, como el hecho de que yo vea una flor amarilla, no es una representación, sino una presentación y, por ende, no es ni verdadera ni falsa, ni falible ni infalible. Aunque el percepto posee una cualidad fenoménica, lo que se presenta no es una imagen o una representación mental, sino (normalmente) una cosa o un hecho real, externo. El percepto combina la primeridad con la segundidad, pues tiene una cualidad fenoménica (primeridad), pero es una interacción entre el perceptor y la cosa o el hecho (segundidad). En cambio, un juicio perceptual, como "eso es amarillo", no 
es una presentación, sino una representación de carácter proposicional, y por lo tanto es verdadera o falsa, falible o infalible. Combina la segundidad con la terceridad, pues su término-sujeto es indicativo (segundidad), pero su expresión-predicado es general (terceridad). Lo que se presenta en el percepto está indicado por el término-sujeto del juicio perceptual. De acuerdo con Peirce, los juicios perceptuales son involuntarios, nos vemos forzados a ellos; pero al mismo tiempo son totalmente interpretativos, y de aquí que, aunque no se puedan corregir, sean totalmente falibles.

Las alucinaciones y las ilusiones pueden resultar fenomenológicamente indistinguibles de la percepción genuina; pueden compartir su cualidad de insistencia, de hallarse en estado bruto; incluso pueden ser experimentadas por más de un individuo. Pero se las distingue por el hecho de que el comportamiento de los objetos reales, externos, de la percepción genuina es predecible con base en nuestro conocimiento de las leyes de la naturaleza.

El realismo escolástico de Peirce es la tesis de que hay generalidades reales, es decir, clases y leyes naturales reales. Esto se opone, evidentemente, al nominalismo, según el cual las generalidades no son reales, sino invenciones. También se opone, aunque menos evidentemente, al platonismo, el cual postula que las generalidades existen. La existencia, según Peirce, es el modo de ser característico de los particulares, los segundos, y por lo tanto el "platonismo nominalista", como irreverentemente lo llama, malinterpreta en forma confusa las generalidades con los particulares abstractos. El realismo peirceano también se contrapone a la idea de que lo verdaderamente real es en principio inaccesible a la cognición humana -el numenalismo, podría decirse. Como lo expresó el mismo Peirce en cierta ocasión, aunque su pragmatismo es afín al kantismo, desecha el Ding an Sich como un "exceso vacuo" (5.525). El realismo peirceano tampoco se parece mucho a su ancestro más cercano, el realismo de Escoto, pues, al contrario de éste, Peirce no supone que puede extraerse de nuestro lenguaje cuáles son las generalides reales, sino que cree que ésta es una cuestión que debe ser descubierta por la investigación científica.

Si no hubiera generalidades reales, argumenta Peirce, la ciencia sería imposible, pues la posibilidad misma de la predicción, la inducción y la explicación depende de la realidad de las clases y las leyes. Hay una pauta de generalidades, de clases y leyes naturales que es independiente de la manera en que se piensa que son, y que subyace en las cosas y los hechos particulares que percibimos. $Y$ en consecuencia el "elemento arbitrario y accidental" de la investigación, introducido por las circunstancias e idiosincrasias particulares de cada investigador, sería superado con el tiempo a medida que aquélla avance (8.13). 
Peirce hizo una importante aportación a la lógica deductiva formal: unificó el cálculo proposicional con la teoría de la cuantificación y desarrolló la lógica de las relaciones más o menos al mismo tiempo que Frege, aunque en forma independiente; llegó a la definición de número que se da en los Principia mathematica, anticipándose a éstos en más de treinta años; concibió las tablas de verdad, descubriendo el operador ahora conocido como el "el operador de Scheffer" y experimentando con la lógica trivalente más de una década antes de Post y Lukasiewicz y con la lógica modal/intencional mucho antes que Lewis o Carnap; incluso anticipó la computadora con su esquema de un diagrama de cableado para una máquina eléctrica de lógica. La concepción peirceana de la lógica es, además, mucho más amplia que la concepción moderna usual, heredada de Frege; abarca temas como el análisis de las proposiciones, que ahora se clasificaría como filosofía de la lógica más que como lógica propiamente dicha, y no está restringida exclusivamente a la lógica deductiva. Más adelante, Peirce consideró la lógica como parte de la semiótica, la teoría general de los signos de la que él fue pionero y que trata de la crítica de los argumentos; posteriormente, llegó a concebir la lógica como semiótica.

El método de la ciencia requiere de la abducción, la formulación de un hipótesis que, de ser verdadera, explicaría un fenómeno desconcertante; de la deducción de las consecuencias de esa hipótesis, y de la comprobación inductiva de esas consecuencias para determinar la probabilidad de que la hipótesis sea verdadera. La investigación científica es creativa; exige imaginación para llegar a las hipótesis abductivas y a los neologismos y cambios de significado que amplían los límites de los recursos lingüísticos heredados por el científico. Pero hay "trillones y trillones de hipótesis" que podrían ser formuladas, de las cuales sólo una es verdadera; tenemos tanto éxito en nuestro quehacer, sugiere Peirce, porque la evolución ha dotado a los seres humanos del instinto de adivinar, el cual "aunque es más común que se equivoque a que acierte, la relativa frecuencia con la que está en lo correcto es [...] lo más maravilloso de nuestra constitución" (5.172-173). Y si bien los experimentos afirmativos no confieren ninguna probabilidad definida a una teoría, y aunque las instancias de una ley no puedan ser agotadas, si se observa regularidad en una serie, se la debe poder descubrir hasta un grado de aproximación indefinida examinando el suficiente número de casos: "la validez de la inducción depende de la relación necesaria entre lo general y lo singular" (1.170).

Peirce no cree que sea precisamente falso decir que la verdad sea una correspondencia con la realidad, pero considera esto una simple definición nominal, que no arroja ninguna luz pragmática al concepto. Él mismo ofrece una definición semejante: "Una proposición tiene sujeto [...] y predicado. 
El sujeto es un signo; el predicado es un signo, y la proposición es un signo de que el predicado es un signo de aquello de lo que el sujeto es un signo. De ser así, es verdadera". Pero inmediatamente después, pregunta: “¿en qué consiste [...] esta correspondencia?", y responde: "Si pudiéramos encontrar el método correcto para pensar y seguirlo [...] entonces la verdad sólo sería, más o menos, el resultado último al que nos conduce el seguimiento de este método" (5.553).

Así, pues, la explicación peirceana del significado pragmático de "verdadero" identifica la verdad con la opinión hipotética final que sería convenida si la investigación continuara indefinidamente. "La verdad es la concordancia de [...] [un] enunciado con el límite ideal hacia el que una investigación incesante tendería a llevar a las opiniones científicas" (5.564). Esto no exige que se llegue de hecho a una opinión final, ni tampoco implica que ninguna proposición sea verdadera hasta que se alcance la opinión hipotética final; una proposición es verdadera ahora si formara parte de la opinión final en caso de que ésta fuera alcanzada. Aun así, con su pretendida adecuación de los dos propósitos deseados de la objetividad y la accesibilidad (de principios), la teoría de Peirce confronta un grave problema: el de los secretos enterrados.

La explicación peirceana implica que una proposición que no pueda ser establecida, por mucho que se siga investigando, no es ni verdadera ni falsa. Pues algunas proposiciones que no podrían ser establecidas a través de la investigación, por prolongada que ésta sea, por ejemplo, que Hamlet estornudó tres veces el día previo a su muerte, esa implicación parece intuitivamente correcta. Sin embargo, con respecto a otras proposiciones que también podrían resultar imposibles de establecer, la implicación se opone a la fuerte intuición de que debe contener un valor de verdad definido, aunque nunca lo podamos descubrir. Antes de la extinción de la especie, dice la intuición, hubo exactamente $n$ dinosaurios; por ende, la proposición que especificara el $n$ adecuado sería verdadera, y todas las demás falsas, sin importar si la cuestión puede ser zanjada o no alguna vez por la investigación.

Quienes hacen esta objeción son demasiado pesimistas con respecto a lo que es posible descubrir, contesta Peirce; no hace mucho (escribe en 1878) se creía firmemente que los astrónomos nunca descubrirían la composición de las estrellas distantes, y lo hicieron. Sin embargo, Peirce no pretende que podría establecerse toda proposición sobre el pasado si la investigación se prolongara el tiempo suficiente. Las proposiciones que realmente se resisten siempre a ser establecidas, sostiene, carecen de sentido pragmático.

Como esto lo indica, la explicación peirceana de la realidad tiene dos caras: la real es independiente de lo que usted o yo o cualquiera cree que es, pero no de lo que la comunidad de investigadores creería si la investigación 
se prolongara el tiempo suficiente. Éste no es el realismo convencional; para tomar prestado el término que usa Peirce cuando describe la postura de su padre, se trata de un "realismo ideal" (Kloesel y Houser, 1992, p. xxxv), un intento de compromiso entre los indeseables extremos del idealismo y el trascendentalismo. "¿Qué significa que existe una cosa llamada Verdad?", pregunta, y responde: "Quiere decir que [...] hay algo que es Así, independientemente de que la gran mayoría vote en contra" (2.135); éste es el aspecto realista de su realismo ideal. Pero también insiste en que "cualquier verdad que sea más perfecta que [la] conclusión predestinada [de la investigación], cualquier realidad que sea más absoluta que lo que se piensa que contiene, es una ficción de la metafísica" (8.13); y éste es el aspecto idealista de su realismo ideal.

William James (1842-1910), hijo del filósofo de origen sueco Henry James y hermano del novelista del mismo nombre, abandonó su primera aspiración de hacer carrera en el arte para estudiar medicina, y no se distinguió menos como psicólogo que como filósofo. Al igual que Peirce, James consideraba que la máxima pragmática era la médula del pragmatismo; pero mientras la filosofía de Peirce maduró en un estilo lógico y (en cierto sentido) realista, la de Joyce evolucionó hacia una vena más psicológica y (en cierto sentido) nominalista. Al contrario de Peirce, James pensaba que la filosofía haría bien en volver a Kant, en vez de pasarlo por alto. Estuvo más influido por los empiristas británicos, y dedicó su Pragmatism a John Stuart Mill, "de quien aprendí por primera vez la apertura mental pragmática y a quien me gusta considerar en mi imaginación como nuestro líder..."

Estas diferencias se reflejan en su interpretación de la máxima pragmática, que subraya la praxis, práctica, las consecuencias prácticas de la aplicación de un concepto: "no puede haber una diferencia en una parte que no marque una diferencia en otra" (1907, p. 30). James y Peirce convienen en que el significado tiene propósito, en que el significado de un concepto yace en su aplicación; pero el Peirce maduro y realista, al contrario de James, considera que esta clase de formulación es infortunada si fomenta la subordinación de "la concepción al acto, del saber al hacer" (1900, p. 332). Y esta diferencia de énfasis se magnifica tremendamente debido a la disposición de James a interpretar "las consecuencias de una creencia" de tal modo que no sólo incluya las consecuencias de la verdad de la proposición creída, sino también las consecuencias de la persona que la cree.

Ésta es la razón por la que los lectores de James tienen a veces dificultades para desenmarañar su pragmatismo de su doctrina de la voluntad de creer. En oposición a la insistencia de W.K. Clifford en que "es incorrecto 
siempre, en todo lugar y para cualquier persona, creer algo con base en evidencias insuficientes", James defiende "nuestro derecho a adoptar una actitud creyente en asuntos religiosos, a pesar del hecho de que nuestro intelecto meramente lógico pueda no sentirse obligado a ello" (1897, pp. 12). Cuando no es posible decidir una hipótesis, por su propia naturaleza, con base en la evidencia, cuando nos significa la vida y nos atrae como una posibilidad real, cuando la elección entre creer y negarla es algo obligado, inevitable y fundamental para nuestra existencia, entonces, sostiene James, "nuestra naturaleza pasional [...] puede decidir [...] legítimamente" (p. 11). La creencia religiosa — que James interpreta, tanto en términos aparentemente éticos como teológicos, como la convicción de que "las cosas mejores son las eternas" y de que estamos en mejores condiciones ahora si creemos que esto es así-, aunque no puede ser en principio verificada ni desmentida, puede ser legitimada por el saludable efecto que ejerce en la vida del creyente.

$\mathrm{Al}$ año siguiente encontramos a Peirce, a quien está dedicado The Will to Believe, describiendo la actitud científica como la "voluntad de aprender" (5.583) y, más adelante, observando que, en lo que a él tocaba, "no adoptaría una hipótesis, ni siquiera durante un periodo de prueba, sólo porque la idea me pareciera agradable", pues esto sería "un crimen contra la integridad de la razón que Dios me ha dado" (5.598). Cabe pensar que lo expresa, si acaso, muy tibiamente, pues según los criterios de la máxima pragmática, como Peirce la interpreta, una hipótesis que en principio no puede ser establecida mediante la observación y el razonamiento no es en modo alguno una hipótesis genuina.

Quizá ésta es la razón de que, a pesar de la insistencia oficial de James en que la voluntad de creer se refiere a la política de la creencia más que al carácter de la verdad y, por lo tanto, en que es independiente del pragmatismo, parece incapaz de mantener consistentemente la separación entre ambas. Pues si se la interpreta como que confiere significado a las consecuencias pragmáticas de la verdad de una proposición, la máxima pragmática debilita a la doctrina de la voluntad de creer; mientras que si se la interpreta como que confiere significado a las consecuencias pragmáticas de la creencia en una proposición, la máxima pragmática se mezcla de hecho con la voluntad de creer.

También asociado (y a veces confundido) con el pragmatismo de James está el "empirismo radical" de su madurez, un intento por escapar del dualismo de la metafísica cartesiana y la subjetividad de la epistemología cartesiana, y por enriquecer la empobrecida concepción de la experiencia de los viejos empiristas. Todo - tanto lo mental como lo físico, según decimos equívocamente- es una construcción a partir de la "experiencia pura", que 
en sí misma no es ni mental ni física. La diferencia entre conciencia y contenido, conocedor y objeto conocido, no es una distinción ontológica de las diversas clases de material, sino una cuestión de relaciones entre diferentes fragmentos de experiencia pura.

Uno de los temas, que no está desarrollado con precisión, sino sugerentemente esbozado, y que anticipa ideas que ahora nos son familiares por los representantes más recientes de la filosofía de la mente, es que constituye un error pensar en la conciencia como en una clase de entidad; se trata más bien de una función. El concepto de conciencia como cosa, escribe James, es "el débil rumor que deja el 'alma' al esfumarse en el aire de la filosofía" (1904, p. 100). Reconociendo sus afinidades con Brentano, señala el hecho de que actitudes proposicionales como la creencia poseen un contenido, están dirigidas a algo externo.

De acuerdo con el empirismo radical, sólo hay una clase de material, la experiencia pura, y diversas relaciones entre los fragmentos de esta única clase de material. ¿Cómo puede una misma clase de material tener a la vez aspectos mentales y físicos? James responde que del mismo modo en que la pintura puede ser, en la tienda, un material vendible y, sobre la tela, una representación pictórica. ¿Cómo puede una y la misma cosa estar a la vez en el espacio y en la mente? James responde que del mismo modo en que uno y el mismo punto puede estar en dos líneas si se encuentra situado en la intersección.

Aunque James no usa el término, Russell reconoce al empirismo radical como precursor de lo que él llama "monismo neutral". Pero si el empirismo radical es una forma de monismo neutral, ¿de qué manera compagina con el "Universo Pluralista" de las Conferencias Hibbert de James? Aunque sólo existe una clase de material, escribe James, hay muchas porciones o fragmentos individuales de éste. La suya es una "filosofía de mosaico", continúa, la cual "pone el énfasis explicativo en la parte, el elemento, el individuo" (1912, p. 24). Aquí, como en otros lugares, muestra una marcada predilección por lo particular y lo concreto sobre lo general y lo abstracto.

Al igual que Peirce, sólo que quizá más enfáticamente, James sugiere que, si bien no es exactamente falso decir que la verdad sea una correspondencia con la realidad, no es ésta una afirmación que satisfaga al pragmatista. "La verdad", escribe, "como lo dice cualquier diccionario, significa la 'concordancia' de una idea con la 'realidad'". El punto en que los pragmatistas difieren de los "intelectualistas" es la manera de explicar lo que esto significa. "El pragmatismo formula su pregunta habitual... '¿Qué diferencia concreta implicará realmente... ? ¿Qué experiencias serán distintas de las que se obtendrían si la creencia fuera falsa? ¿Cuál, en suma, es el valor de la creencia en moneda corriente?" (1907, p. 96). 
James distingue la verdad absoluta de las verdades concretas. Caracteriza a la primera como "un conjunto ideal de formulaciones hacia el cual cabe esperar que, a largo plazo, van a converger todas las opiniones" (1909, p. 143), caracterización que recuerda a la de Peirce, salvo por el hecho de que James habla, quizá descuidadamente, de convergencia en vez de consenso. Pero James no se parece mucho a Peirce cuando escribe que la diferencia entre creencias verdaderas y falsas consiste en que las verdaderas son "verificables"; y es totalmente distinto de Peirce cuando explica que las creencias verdaderas son las que nos guían correctamente, y que lo verdadero es sólo lo satisfactorio, lo útil, lo provechoso en la forma de creencia, que las creencias verdaderas funcionan.

Críticos como Moore y Russell, perturbados por la referencia de James al "valor en moneda corriente" de las creencias verdaderas, lo interpretaron como que cualquier cosa que le acomode a uno creer es verdadera, y señalaron, desde luego correctamente, que algunas creencias son verdaderas pero no útiles, mientras que otras son útiles pero no verdaderas. Les escandalizó lo que consideraron como una crasa identificación de la verdad con la utilidad, itan vulgar, tan típicamente estadounidense! Pero James, quejándose de los incomprensivos lectores que insisten en dar la interpretación más tonta posible a sus palabras, califica tales críticas de "calumnias" (1909, p. 147), pues aunque realmente había escrito que "la verdad [...] sólo es provechosa en forma de creencia", había procedido a explicar: "provechosa a largo plazo y en general, desde luego, pues lo que satisface de manera provechosa toda la experiencia que está a la vista no satisfará necesariamente toda la experiencia ulterior con igual adecuación. La experiencia [...] tiene maneras de bullir y hacernos corregir nuestras fórmulas presentes" (1907, p. 106).

La solidez de su respuesta depende crucialmente de la capacidad de James para mantener su explicación firmemente anclada en el futuro lejano de la experiencia. Pero éste, en el mejor de los casos, es limitado. James se disocia del carácter inconexo de sus primeros empirismos y, específicamente, de las tesis de que los similares no tienen en realidad nada en común y de que el lazo causal no es más que una conjunción habitual; así, bien podría, como Peirce, haber recurrido a la realidad de las clases y leyes para sostener su concepción de la verdad absoluta. Incluso reconoce que "admitir, como lo hacen los pragmatistas, que estamos sujetos a corrección [...] implica el uso, por parte nuestra, de un criterio ideal" (1909, p. 143). Sin embargo, su predilección por lo particular lo lleva a insistir en que los pragmatistas se concentren en las verdades concretas, dejando que los "intelectualistas" se preocupen por la verdad abstracta; y su incomodidad con la noción de 
lo verificable refuerza esta preferencia por las verdades concretas realmente verificadas.

Cuanto más se concentra James en las verdades concretas, desdeñando la verdad abstracta, y cuanto menos claramente toma en cuenta la dependencia entre el primer concepto y el segundo, más graves son sus dificultades. Aunque a veces reconoce que las creencias que están verificadas demuestran con esto que han sido siempre verdaderas, a menudo indica que las creencias se vuelven verdaderas cuando son verificadas. Así: "La verdad le sucede a una idea. Ésta se vuelve verdadera, es convertida en verdadera por los hechos. Su veracidad es en realidad un hecho, un proceso, a saber, el proceso verificador mismo, su veri-ficación" (1907, p. 97).

Y cuando escribe que "debemos vivir hoy de acuerdo con la verdad que podamos obtener actualmente, y estar dispuestos a llamarla mañana falsedad", convierte "verificado" en "confirmado", concediendo que, al fin y al cabo, lo que está verificado puede no ser verdadero. Esa conversión lo tienta, probablemente, porque explicar "verificado" en el sentido de "demostrado como verdadero" le exigiría cimentar su concepción de las verdades concretas en la verdad abstracta, a cuyo respecto James parece muy ambivalente. Pero, desde luego, si "verdad concreta" sólo significa una "creencia confirmada en el presente", no es necesariamente ninguna verdad en lo absoluto, lo cual es sin duda la razón de que James recurra a sus inquietantes comillas y empiece a escribir, no de verdades concretas, sino de "verdades" concretas.

Esto no resuelve en modo alguno todas las dificultades, pero contribuye en cierta medida si, tomando en serio esas inquietantes comillas, ubicamos las reflexiones de James sobre las "verdades" concretas en el contexto de su pensamiento (también estructurado de manera bastante vaga, pero a la vez ricamente sugestivo) acerca de los procesos de la investigación. Cuando investigamos, escribe James, injertamos nuevas creencias en un viejo tronco; sostenemos que una teoría es verdadera "sólo en proporción al éxito que tiene para resolver [el] problema de la máxima y la mínima" (1907, p. 35), vale decir, en la medida en que logra preservar al máximo lo que antes creíamos verdadero y modificar lo mínimamente posible el tronco de creencias existentes.

Se observan ciertos paralelos entre el problema de la máxima y la mínima de la epistemología de James y su ensayo ético, cautivadoramente pluralista, "The Moral Philosopher and the Moral Life". Los valores morales, de acuerdo con James, aunque no son en sí mismos subjetivos, surgen de los deseos y evaluaciones subjetivos de agentes individuales: "la esencia del bien no es más que satisfacer una demanda" (1891, p. 311). Como las demandas, los deseos y las preferencias de las personas son encontrados, 
el problema central de la ética consiste en maximizar la satisfacción de los deseos mientras minimiza la insatisfacción.

En el mismo escrito, James comenta que las discusiones filosóficas en torno a problemas y dilemas morales específicos se alían con los sermones, los libros sobre política y filantropía y "las novelas y los dramas de corte más profundo" (p. 316); ésta es una anticipación muy modesta de lo que llegaría a ser, en una de las ramas del neopragmatismo contemporáneo, un intento revolucionario por disociar el pragmatismo de la ciencia y asimilarlo a la literatura.

Hay, en los escritos de James, un aire general de enfado, de impaciencia con "el pusilánime sentimentalista y soñador, que nunca lleva a cabo un hecho concreto valeroso" (1890, p. 66). Dos de los escritos menos conocidos, pero más curiosos de James ponen de manifiesto lo agudamente que comprende y lo genuinamente que aprecia la diversidad humana: "On a Certain Blindness in Human Beings", en el que defiende en elocuentes términos la tolerancia hacia los valores de los demás, por extraños e insensatos que nos puedan parecer; y "On the Value of the Individual", celebración de la riqueza de las diferencias humanas.

Como esto lo indica, y como también nos lo recuerda la observación de Peirce de que "el hombre es esencialmente un ser social: pero ser social es una cosa, y ser gregario otra" (1.11), los viejos pragmatistas no eran tan unidimensionalmente comunitarios como parecen serlo algunos neopragmatistas contemporáneos.

John Dewey (1859-1952) no provenía de una familia de intelectuales, como Peirce o James, sino de una familia de agricultores de Vermont. Su pensamiento evolucionó gradualmente, bajo la influencia de los Principles of Psychology de James y de la obra de Darwin, de un idealismo hegeliano inicial a un naturalismo filosófico posterior. Peirce también ejerció una marcada influencia; maduró con relativa lentitud, pero, finalmente, observando el énfasis de Peirce en el fenómeno experimental general más que en el resultado particular de los experimentos, su profunda estima por la lógica, su comprensión explícita del carácter social de la investigación y su rechazo a la voluntad de creer, Dewey terminó por considerar a Peirce "más pragmatista que James" (1916, p. 76).

Dewey caracteriza su estilo de pragmatismo como "instrumentalismo". No usa el término en el sentido moderno, el cual hace referencia a la tesis de que los "enunciados" teóricos en la ciencia no son en modo alguno enunciados auténticos, sino sólo herramientas para realizar predicciones basadas en la observación; era más bien una forma de aludir a la preocupación pragmática por la cuestión de "cómo funciona el pensamiento en la determinación 
experimental de la conducta futura". Busca una "integración [...] entre las creencias del hombre sobre el mundo en que vive y sus creencias acerca de los valores y propósitos que deben guiar su conducta" (1929, p. 225). Esto se entreteje con el énfasis en la continuidad que también se observa a lo largo de toda su obra y con su desconfianza hacia los dualismos filosóficos tradicionales: mente contra cuerpo, teoría contra práctica, razón contra experiencia, y hecho contra valor.

Dewey advierte que el insostenible dualismo entre mente y cuerpo coadyuva desastrosamente a "la división entre religión, moral y ciencia" en la filosofía occidental, e insiste en que pensemos, en cambio, en "la vida en operación [y] el cuerpo [...] como el mecanismo, la instrumentalidad del comportamiento, la mente como su función, su fruto y consumación" (1931, p. 301). Consideramos erróneamente la acción — convertimos a la conciencia en un misterio - si pensamos en forma atomista, en términos de reacción a los estímulos. La unidad del comportamiento es, más bien, una "acción que implica al organismo entero". (Se podría ofrecer a Dewey la mecanografía al tacto, como una clara ilustración de un acto en que lo mental y lo físico se encuentran homogéneamente amalgamados.)

Peirce había escrito que "toda mi filosofía siempre ha parecido emanar de una falibilismo contrito, combinado con una elevada fe en la realidad del conocimiento" (1.14), y James que "cuando [...] renunciamos a la búsqueda de la certidumbre, no por ello renunciamos a la búsqueda o la esperanza de la verdad misma" (1897, p. 17). En The Quest for Certainty, Dewey emprende el mismo camino falibilista y, en un sentido amplio, desde el mismo punto de partida de Peirce, desde una concepción de la investigación como un proceso que va de la duda a una creencia establecida.

Los escritos epistemológicos de Dewey son críticos, no sólo del cartesianismo, sino de toda la tradición epistemológica, desde Platón, pasando por Descartes, hasta sus propios contemporáneos. La idea de que el único conocimiento que vale la pena tener es el conocimiento cierto, sugiere Dewey, es el legado de la aguda dicotomía entre la teoría y la práctica, encarnada en la cultura esclavista de la antigua Grecia. Platón y Aristóteles emprendieron una sistematización racional de las ideas religiosas, eliminando lo mítico y estructurando los ideales de ciencia y razón. Pero el precio fue la glorificación de lo invariable, lo cierto, lo intelectual, así como la denigración de lo mutable, lo meramente probable, lo práctico.

Toda esta tradición, según Dewey, descansa sobre una falsa analogía entre saber y ver, la teoría del conocimiento del espectador. "Las teorías especiales del conocimiento difieren inmensamente entre sí. Sus polémicas [...] llenan el aire. La batahola así creada nos vuelve sordos de tal manera que todas expresan una misma cosa en común [...] Todas sostienen que el 
funcionamiento de la investigación excluye cualquier elemento de actividad práctica..." (1929, p. 22). Dewey, en cambio, insiste en que saber no está aislado de esa actividad, sino que es en sí mismo una especie de práctica.

Dewey nos recuerda menos a Peirce cuando, después de señalar que la investigación es una especie de práctica, que ha de ser juzgada, como otras prácticas, por el éxito en sus propósitos, agrega: por el éxito en sus propósitos más que por algún presunto criterio de precisión en la reflexión de sus objetos. El objeto del conocimiento no es una realidad inmutable e independiente, sino que en parte está constituido por nuestras interacciones cognitivas con aquélla. La investigación, al descubrir "hechos provisionales" y conjeturar posibles soluciones, transforma una problemática situación indeterminada en otra determinada. Esto logra parecer radical, como si, al igual que se disipa una situación peligrosa quitándole la pistola al lunático, transformar una situación problemática en otra determinada cambiara sustancialmente al mundo; y al mismo tiempo trivial, como si, al igual que cuando se comprende una situación desconcertante, no cambiara al mundo, sino sólo nuestra relación con él.

Tanto Peirce como James habían intentado, por diferentes vías, desarrollar una concepción de la experiencia más rica que la magra idea de la "idea" del empirismo clásico. Dewey habla plausiblemente de la necesidad de casar lo mejor del racionalismo con lo mejor del empirismo. La razón y los sentidos no deben ser pensados como competidores que buscan ocupar la primera fila, sino como aliados en la investigación. Es mejor, no obstante, pensar en términos de inteligencia y buen juicio que en términos de razón o nous, y esencial para entender que la experiencia es activa y experimental, una cuestión de lo que se toma, no de lo que se da. Una investigación productiva exige manipulación, experimentos, instrumentos, una tamización constante de las creencias de fondo, la habilidad para seleccionar los conceptos. Sin embargo, también en este punto Dewey parece dar un paso más radical, desde la idea de que la experiencia es activa en el sentido de que exige una manipulación, una experimentación y una selección inteligentes, hasta la idea de que constituye en cierta forma sus objetos. A su reparo de que la teoría del espectador "excluye cualquier elemento de actividad práctica", añade: "actividad práctica que entra en la construcción del objeto conocido".

"¿Por qué", pregunta retóricamente, "la idea de que el conocimiento marca una diferencia para y en las cosas debe ser objetable de antemano?" No es objetable en modo alguno, argumenta, en cuanto se concede que el mundo se encuentra en constante cambio; pero no ofrece ningún argumento acerca de que el conocimiento sea el agente del cambio. Peirce lo desaprueba: "[h] ay ciertos pedantes momificados que nunca han comprendido la ver- 
dad de que el acto de conocer un objeto real altera a éste. Son curiosos especímenes de la humanidad, y [...] yo soy uno de ellos" (5.555).

Como Peirce, Dewey concibe la lógica en términos amplios, como la "teoría de la investigación", de la cual la lógica deductiva formal — la lógica en el sentido moderno usual - es sólo una parte. Peirce criticó la lógica de Dewey, aunque no porque no fuera formal, sino porque se limitaba excesivamente a lo descriptivo, de modo que equivalía sólo a una "historia natural" de la investigación, no una metodéutica normativa. Pero en cualquier caso, para el momento de la publicación de Logic: The Theory of Inquiry, Dewey parece reconocer claramente que la lógica es normativa, si bien subraya que las recomendaciones acerca de cómo debe llevarse a cabo una investigación sólo pueden estar basadas en el estudio científico de cuáles son los procedimientos cuya eficacia ha sido probada.

Dewey califica una de las caracterizaciones peirceanas de la verdad - "[1]a opinión que está destinada a recibir el acuerdo de todos los que investigan" (5.407) — como "la mejor definición" (1938, p. 345n.). Pero, como James, tiende a preferir lo concreto a lo abstracto, la verificación real a la verificabilidad potencial, las verdades a la Verdad. Gran parte de sus escritos parecen ambivalentes entre lo más y lo menos radical. El horror que tiene el intelectualista de reconocer que, como lo indica la etimología, la verificación es cuestión de convertir una creencia en verdadera, es, en su opinión, "fundamentalmente sentimental"; pero acto seguido explica que convertir una idea en verdadera "es modificarla y transformarla", supuestamente para cambiar la proposición implicada, hasta que pueda pasar la comprobación (1910, p. 139). Sostiene que, al verificarse una creencia, se demuestra que ésta ha sido siempre verdadera, pero entonces explica que esto sólo significa que iba a ser verificada (pp. 142-144). Aunque el pragmatista niega que la verdad sea una correspondencia del pensamiento con las cosas en sí mismas incognoscibles, escribe Dewey, no niega que la verdad sea una correspondencia del pensamiento con la existencia; sin embargo, agrega, se trata de una co-respondencia, un "interajuste" de nuestras ideas a situaciones problemáticas (pp. 158-159). No es de sorprender, pues, que se sienta atraído por la idea de que bien podría dejarse de lado "verdad" y usar en su lugar "aseverabilidad autorizada".

En el capítulo de The Quest for Certainty que confronta más directamente la cuestión de la ciencia y los valores, "La construcción del bien", Dewey observa que "restablecer la integración [...] entre las creencias del hombre sobre el mundo en que vive y sus creencias acerca de los valores y propósitos que deberían guiar su conducta constituye el problema más profundo de la vida moderna" (1929, p. 225). Se oye nuevamente el tema de la mediación entre el racionalismo y el empirismo, ahora como un compromiso entre la 
construcción de valores en tanto abstractos y trascendentes, y su reducción a simples preferencias en bruto. Y quizá también resuena algo de James cuando Dewey argumenta que los valores se basan en lo que la gente desea, pero que no se reducen a esto. De la misma manera en que lo comestible no es simplemente cuestión de lo que se come, sino de lo que, a la larga, satisface el hambre sin dañar al organismo, tampoco lo deseable es sólo cuestión de lo que se desea, sino de lo que, a la larga, satisface nuestros deseos sin dejarnos un "regusto de amargura" (p. 267).

Algunos podrían preguntarse si la relación de lo comestible con lo que se come es exactamente igual a la relación de lo deseable con lo que se desea; y algunos querrían que se argumentara mejor la afirmación de que los valores morales deben estar enfocados, como lo supone Dewey, a la prosperidad humana. Pero muchos encontrarán algo atractivo en la idea del bien como lo que conduce realmente a la prosperidad humana y, por ende, de la investigación científica como una actividad que puede contribuir a nuestro entendimiento de lo que es genuinamente bueno.

Como cabría esperar, dada la insistencia de Dewey en que la filosofía no pierde contacto con la vida, sus intereses filosóficos profundizan en asuntos sociales y políticos. Y no sólo sus intereses filosóficos: fue un activo reformista social, que participó en las labores del centro comunitario [Hull House] de Jane Addams en Chicago, en la fundación de la Asociación Estadounidense de Profesores Universitarios, en el Consejo Estadounidense de Libertades Civiles y en la Nueva Escuela de Investigación Social, además de formar parte de la comisión enviada a México a investigar las acusaciones de Stalin contra Trotsky.

Cuando Dewey escribe sobre el renacimiento o la reconstrucción de la filosofía, una de sus aspiraciones recurrentes consiste en sustituir la vieja búsqueda de certezas inmutables por una aplicación más flexible y adaptable de la inteligencia. Sin embargo, también hay un tema más radical, desarrollado agudamente en un ensayo de 1919, "Philosophy and Democracy", que Dewey abre con una excelente interrogante: "¿Por qué filosofía y democracia, en vez de química y oligarquía, matemáticas y aristocracia, astronomía y monarquía?" Responde que la filosofía se concibe mejor, no como una rama de la ciencia, sino como el amor por la sabiduría: "un deseo intelectualizado, una aspiración sujeta a discriminaciones y pruebas racionales, un programa social [...] disciplinado por un pensamiento y un conocimiento serios" (1919, pp. 71, 73). La filosofía, así concebida, implica el ejercicio de la imaginación moral, "una sensibilidad hacia el estilo de vida mejor que pueda ser llevado" (p. 74). Para Dewey, esto significa en parte una exploración del significado y el valor de la democracia. 
Dewey nunca olvida la importancia de la investigación como base de un cambio social inteligente y eficaz. Es optimista con respecto a las perspectivas de una investigación sociocientífica realizada correctamente, por lo menos siempre que sea posible curar a las ciencias sociales de su inadecuada ambición de ser exactas como la física; pero es consciente de que, en vista de la inevitable falibilidad de tal investigación, el gradualismo resultaría probablemente preferible a un cambio revolucionario.

Cuando Dewey habla de democracia, es en un sentido muy amplio, como algo mucho más que una forma o una clase de formas específicas de gobierno: es un sentido que se extiende a la familia, la escuela, la industria y la religión (1927, p. 293). Sobre este tema, Dewey en ocasiones parece caer en una especie de misticismo romántico, pero resulta iluminador cuando observa el reconocimiento encubierto del valor de la democracia en los intentos soviéticos y nazis por secuestrar el término para sus regímenes totalitarios, cuando comenta la importancia que posee para una democracia auténtica la manera de llegar al consenso, así como la manera de organizar las votaciones, o cuando escribe que "el principio fundamental de la democracia es que los fines de la libertad y la individualidad para todos sólo pueden alcanzarse por medios que estén de acuerdo con esos fines" (1937, p. 338). Como lo demuestra esto último, a pesar de su desagrado hacia lo que llama el "individualismo irregular", la concepción de Dewey es menos una concepción del individuo como subordinado a la comunidad que del individuo y la comunidad en tanto interdependientes; en este contexto, hace una admirativa referencia a James.

James había pronunciado conferencias para maestros, Talks to Teachers, y escrito con mucha perspicacia acerca de los tentáculos usurpadores del "pulpo del doctorado"; Peirce se había referido reflexivamente al objetivo de la universidad. Pero sería Dewey el filósofo de la educación más influyente del pragmatismo, y en realidad, de Estados Unidos. Su desconfianza hacia los dualismos fáciles se vuelve a poner en funcionamiento cuando defiende un enfoque intermedio entre los dos extremos de la teoría de la educación: el enfoque exclusivo en la materia de estudio y el enfoque exclusivo en el carácter del niño; en este contexto, Dewey habla otra vez de la necesidad de un "interajuste".

Como lo indica el título de su obra Democracy and Education, Dewey considera que la filosofía social está íntimamente relacionada con la filosofía de la educación: la educación como un medio de reforma social, una contribución a la democracia, y los valores democráticos — confianza en la inteligencia del hombre común, oportunidades para todos a fin de que desarrollen sus talentos- como inspiradores de la educación. Dewey cree que la escuela tiene que desempeñar un papel moral: debe permitir al niño no 
sólo convertirse en un ciudadano responsable y un elector inteligente, sino también "reconocer lúcidamente todas sus relaciones sociales y participar en su sostenimiento (1909, p. 246). En retrospectiva, se advierte el peligro de que esto alentara la politización de la educación.

George Herbert Mead (1863-1931), fue hijo de un ministro que posteriormente se convirtió en profesor de homilética —el arte de predicaren el Seminario Teológico de Oberlin. Trabajó como maestro de escuela y encuestador antes de entrar a Harvard en 1887 para estudiar con Royce y James. En 1891 empezó a dar clases en la Universidad de Michigan, donde fue colega de Dewey; en 1894 pasó, junto con éste, a la Universidad de Chicago.

Al igual que Peirce y James, Mead fue un científico además de filósofo, y actualmente se lo considera uno de los fundadores de la psicología social. Su obra filosófica más importante fue su teoría unificada del lenguaje, la mente, el yo y la conciencia. Ésta tiene afinidades con la crítica peirceana a la conciencia intuitiva del sí mismo sobre la que descansaba la epistemología cartesiana; con la explicación funcional de la conciencia de James; con la concepción de Dewey sobre la unidad del comportamiento, aunque ésta podría ser una forma engañosa de expresarlo, dada la reconocida deuda de Dewey con el pensamiento de Mead en estos temas; y con el énfasis de Royce en la naturaleza social del yo y la moralidad.

El conductismo social de Mead es también en parte una constructiva reacción contra el tipo más conocido de conductismo que se asocia con J.B. Watson. A Mead, el conductismo de Watson le parece demasiado individualista, porque se abstrae del contexto social de las acciones, y demasiado atomista, porque se centra en el artificial par de estímulo y respuesta, en vez de usar el concepto más amplio de la acción como un todo. Sin duda, Mead recuerda mucho a Watson cuando caracteriza como "peculiarmente psicológico" lo que es accesible en la experiencia del individuo (1934, p. 5). El suyo es un conductismo heterodoxo que, en lugar de negar lo interno, lo reconoce bajo la forma de "actitudes", los inicios internos de los actos abiertos.

Mead pinta un complejo cuadro del lenguaje, la mente y la conciencia de sí mismo, como surgido de las interacciones sociales de los seres humanos, y de esas interacciones como una continuación de las de otros animales, si bien van más allá que las de éstos. "El lenguaje, en el que nuestros significados surgen casi exclusivamente en la conciencia, no son sino una forma —altamente especializada - del gesto [...] en esas manifestaciones de las actitudes de otros y de las nuestras, tenemos el material con el que se cons- 
truye el yo, y [...] la conciencia del significado está [...] en última instancia ligada a la conciencia de sí mismo" (1910, p. 349).

El primer elemento de la explicación de Mead, derivado de Wundt, es el concepto de gesto, el cual enriquece el concepto de expresión (como en la obra de Darwin sobre la expresión de la emociones en el hombre y los animales) con referencia al contexto social en el que funciona. Un gesto es el tipo más simple de acto social. Un perro gruñe, otro responde enseñando los dientes, y se sigue una pelea. En esa "conversación de gestos", cada animal responde a la conducta del otro, pero todavía no hay intención ni reconocimiento de la intención.

La simbolización, el significado, sólo aparece cuando una persona reconoce lo que quiere decir el gesto que hace a otra, como un hombre que blande su puño frente a otro, consciente de lo que parecerá su acto desde la perspectiva de éste. Los gestos vocales son especialmente importantes porque, al contrario de las expresiones faciales y otras, no son menos accesibles para el hablante que para la persona a quien van dirigidos, posibilitando que el primero tome conciencia de sus propias actitudes de respuesta a medida que contestan, controlan e interpretan los gestos del otro.

Cuando posee el tipo adecuado de aparato neurofisiológico y se dan las clases correctas de interacciones con los demás, un individuo biológico adquiere el lenguaje y se convierte en un organismo con mente, en un yo. Una persona se vuelve un yo a medida que aprende a responder a sí misma como lo harían otros, y comienza a pensar a medida que aprende a entablar una conversación interna, un diálogo consigo mismo o, más bien, un diálogo entre "yo" y "mí mismo". El "yo" es el yo en tanto sujeto de la conciencia; el "mí mismo" es el yo en tanto objeto de la conciencia, primero ante los demás y después ante el "yo". "El 'yo' es la respuesta del organismo a las actitudes de los otros; el 'mí mismo' es el conjunto organizado de actitudes de otros que uno asume para sí", expresa Mead; "[1] as actitudes de los otros constituyen el 'mí mismo' organizado, y luego uno reacciona hacia esto como un 'yo'" (1934, p. 175).

Algunos se sentirán inclinados a objetar que cuando Mead afirma que el significado surge en el momento en que una persona reconoce lo que quieren decir sus propios gestos para los demás, comete una petición de los principios esenciales; muchos desearían una mayor explicación de "surge". Pero los lectores acostumbrados a los desconcertantes debates contemporáneos de la filosofía de la mente - el naturalismo fuerte contra el moderado, el reduccionismo contra el eliminacionismo y contra el funcionalismo, las "guerras de conciencia" y todo lo demás- quizá encuentren muchos elementos provechosos en el intento de Mead por comprender la manera en que las complejidades de nuestro aparato neurofisiológico y de nuestras 
interacciones sociales operan en forma conjunta para hacernos distintivamente humanos.

En Italia se produjo un debate entre los admiradores del pragmatismo de corte más peirceano (Mario Calderoni, Giovanni Vailati) y los de corte más jamesiano (Giovanni Papini, Giuseppe Prezzolini), en el que el último grupo fue mucho más allá que James, celebrando el "poder supremo" de la voluntad sobre la creencia. Y así, de una forma muy exagerada, el énfasis de James en lo práctico, lo trabajoso, marcó incluso a Mussolini, confirmando indudablemente los peores temores de Russell. La obra de Peirce tuvo cierta influencia en Gran Bretaña a través del joven Frank Ramsey, quien se basó en el concepto de la creencia como un hábito de acción, concepto que Peirce había tomado de Alexander Bain. Pero el principal pragmatista que influyó en Wittgenstein fue James. De joven, Wittgenstein leyó con profunda admiración The Varieties of Religious Experience, y estaba familiarizado con Principles of Psychology, que durante una época fue el único libro de filosofía en su biblioteca, así como con Psychology: The Briefer Course, conocido como el "pequeño Jimmy".

Cuando, en Sceptical Essays, Russell observa que "los tres fundadores del pragmatismo difieren enormemente inter se", no estaba pensando en Peirce, James y Dewey, sino en "James, Schiller y Dewey, respectivamente protagonistas religioso, literario y científico [del pragmatismo]" (p. 61). Se refiere a Ferdinand Canning Scott Schiller (1864-1937). Nacido en SchleswigHolstein y educado en Gran Bretaña, Schiller dio clases primero en Oxford y posteriormente en la Universidad del Sur de California. Peirce observó que Schiller "no comprende muy cabalmente la naturaleza del pragmatismo", e incluso James concedió que la de Schiller era la versión "de los últimos cuando pasan al frente". Russell caracterizó a Schiller como "un ramplón y un vulgarizador de todo lo que toca". Sin duda, el pragmatismo radical y humanista de Schiller es más atrevido y crudo que el de James o Dewey, ya no se diga el de Peirce; muy probablemente, sus vulgarizaciones provocaron las hostiles reacciones de Russell y Moore hacia el pragmatismo en general.

Russell califica a Schiller de protagonista literario del pragmatismo, no porque éste tuviera alguna idea seria de unir la filosofía a la literatura, sino por su afición a las quintillas jocosas y las comedias breves de corte filosófico: quintillas y comedias que se burlaban de las extravagancias de otros filósofos. El hegeliano británico F.H. Bradley, su bete noir particular, es un blanco frecuente:

Un sobrio sujeto de Merton, llamado B-

Se enamoró locamente del Absoluto.

Escribió un grueso libro, 
Alabando sus perfecciones.

El Absoluto lo miró con tristeza.

Peirce, que había escrito (5.17) que "para ser profundo, es requisito ser aburrido" - tenía en mente los secos detalles de su lógica de los relativosse quejó de que los nuevos pragmatistas eran demasiado "vivaces". En 1905 expresó que "el apóstol del Humanismo dice que los filosofistas profesionales 'han hecho a la filosofía a su imagen y semejanza, abstrusa, árida, abstracta y abominable'. Pero pienso que algunas ramas de la ciencia no estarían sanas si no fueran abstrusas, áridas y abstractas" (5.536); y en 1908: “[m]e parece una lástima que [el señor Schiller y los pragmatistas de hoy] permitan que la filosofía se vuelva tan llena de vida que acabe infectada por las semillas de la muerte, con nociones como [...] la mutabilidad de la verdad" (6.485).

Pues en los escritos de Schiller hay una identificación directa de la verdad con la verificación, y un compromiso inequívoco con la construcción, y la mutabilidad, de la verdad. En la medida que Schiller reconoce la verdad abstracta, parece interpretarla como una simple construcción a partir de las verdades concretas. Niega abiertamente que la verdad sea una correspondencia con la realidad, idea que describe no sólo como inútil en tanto criterio, sino también como absurda en sí misma. La verdad es trabajo práctico, es verdad humana, incapaz de surgir sin el esfuerzo y la intervención del hombre. "Verdad" significa "valorado por nosotros", que "propicia nuestros fines". En consecuencia, es mutable, pues las proposiciones se vuelven verdaderas sólo cuando se las aplica con éxito; "una verdad que no [...] se somete a verificación, no es aún una verdad en modo alguno" (1907, p. 8). Y la realidad también es mutable, pues crece a medida que crece la verdad. Así como la verdad es dependiente de nosotros y relativa a nuestros propósitos, también lo es la realidad; los hechos no son descubiertos, sino seleccionados, y hasta construidos, por nosotros.

El término predilecto de Schiller para su estilo de pragmatismo es "humanismo". Abiertamente relativista, se alía con Protágoras, diciendo a sus lectores que, de hecho, el hombre es la medida. Resulta tentador, en retrospectiva, caracterizarlo como el pragmatista vulgar original.

Otro de los discípulos de Royce, Clarence Irving Lewis (1883-1964), suele ser considerado el último de los pragmatistas clásicos. En 1920, después de dar clases en las universidades de Colorado y California, Lewis volvió a Harvard, donde había obtenido su doctorado en filosofía en 1910, para editar los escritos de Peirce (con los que pasó uno o dos años, aunque no fue él, sino Hartshorne y Weiss quienes finalmente publicaron los seis primeros 
volúmenes de Collected Papers). Fue profesor "Edgar Peirce" de filosofía en Harvard hasta que se retiró en 1953.

El propio Royce se clasifica mejor como hegeliano que como pragmatista. Pero las dos corrientes se entretejen en lo que él llama su "pragmatismo absoluto", según el cual "toda nuestra interpretación de la experiencia está determinada, en un sentido afín a lo que Kant definió, por ciertos modos de nuestra propia actividad", es decir, postulados que establecemos para satisfacer las necesidades humanas (1908, p. 238); de aquí que Peirce comente que "la insistencia [de Royce] en el elemento del propósito de los conceptos intelectuales es esencialmente la postura pragmática" (Ladd-Franklin, 1916, p. 720).

Royce alentó a Lewis a estudiar lógica, y es probablemente por su trabajo con respecto a los sistemas modales que actualmente se lo recuerda más. Pero también escribió sobre epistemología, metafísica y ética, y su curso sobre la Crítica de la razón pura de Kant fue famoso en varias generaciones de estudiantes de Harvard.

La teoría de Lewis sobre el conocimiento empírico, aunque pueda parecer sorprendente, es clásicamente fundacionalista; nuestro conocimiento del mundo externo es "un edificio como el Empire State construido con mondadientes", que en el fondo descansa sobre las percepciones de una determinada experiencia en bruto. El aporte distintivo que Lewis hizo al pragmatismo radica, más bien, en su concepción del a priori. Conviniendo en que la mente impone orden a la experiencia, se aparta de Kant al mantener que pueden existir "sistemas conceptuales opcionales [...] que son igualmente objetivos e igualmente válidos"; la elección de uno u otro está determinada "por bases pragmáticas" (1929, p. 271). De aquí su actitud flexiblemente receptiva hacia las opciones a la lógica clásica: "la ley del medio excluido formula nuestra decisión de que cualquier cosa que no esté designada por un cierto término estará designada por su negativo [...] Nuestro rechazo de [...] [una] división tripartita no hace sino reflejar nuestra afición por la simplicidad" (1923, p. 365).

Los pragmatistas de la generacion intermedia, como Sidney Hook y Charles Morris, están actualmente un poco olvidados, y es más frecuentemente W.V.O. Quine - sucesor de Lewis como profesor "Edgar Peirce" en Harvardquien es considerado representante de los descendientes del pragmatismo clásico. En parte esto se debe al último párrafo de "Two Dogmas of Empiricism": "Carnap, Lewis y otros asumen una postura pragmática con respecto a la cuestión de escoger entre diversas formas del lenguaje [...] pero su pragmatismo se desvanece en la imaginaria frontera entre lo analítico y lo 
sintético. Al repudiar esa frontera, yo me adhiero a un pragmatismo más completo" (1951, p. 46).

Aunque la postura de Quine es efectivamente más radical que la de Lewis y la de Carnap, "un pragmatismo más completo" resulta un poco exagerado. Por una parte, mucho antes de la publicación de "Two Dogmas", Peirce había criticado la distinción kantiana entre lo analítico y lo sintético como "totalmente confusa" (5.176); y el año previo a la publicación de "Two Dogmas", Morton White había criticado la distinción en un artículo, cuyo título, "The Analytic and the Synthetic: An Untenable Dualism", manifiesta la influencia de Dewey. Por otra parte, resulta difícil tomar la referencia de Quine al pragmatismo como si tuviera una intención seriamente histórica, dado que incluye a Carnap, quien, desde cualquier punto de vista, es sin duda más positivista que pragmatista. En cierta ocasión Quine escribió una pieza por encargo, titulada "The Pragmatists' Place in Empiricism", pero las referencias al pragmatismo fueron eliminadas cuando el artículo se reprodujo parcialmente bajo el título de "Five Milestones of Empiricism".

Aun así, hay temas en la obra de Quine que recuerdan mucho a Peirce. Había reseñado algunos volúmenes de Collected Papers cuando aparecieron por primera vez, y más adelante expresó que había escrito su reseña del cuarto volumen "a regañadientes" (1985, p. 114); el desorden de los escritos lógicos de Peirce es, evidentemente, ajeno al ordenado temperamento de Quine. No obstante, parece haber absorbido algunas de las ideas filosóficas de Peirce y, como cabía esperar, les dio algunos giros característicamente quineanos.

En sus escritos sobre las clases naturales, por ejemplo, no resulta un capricho de la imaginación discernir cierta afinidad con el realismo escolástico de Peirce. En todo caso, la primera mitad de "Natural Kinds" parece peirceana, pues Quine relaciona los conceptos de clase, similitud, proyectabilidad de los predicados, inducción, disposiciones, condicionales subjuntivos; argumenta que, por razones evolutivas, cabe esperar que el intervalo de las cualidades innatas de los seres humanos corresponda por lo menos aproximadamente con las clases naturales reales; y sugiere que ésta es la respuesta a "ese aspecto del problema tradicional de la inducción que tiene sentido". Sin embargo, estas tendencias realistas son acalladas por las predilecciones nominalistas de Quine y su alergia extensionista al modo subjuntivo, de modo que en la segunda mitad del artículo parece retroceder, asegurándonos que el discurso sobre clases naturales y disposiciones se irá esfumando a medida que avance la ciencia. Como resultado de esto, su compromiso con el realismo, aunque lo exige inequívocamente su explicación del éxito de la inducción, debe ser juzgado como equívoco y confuso. 
Tampoco es un capricho de la imaginación discernir cierta reminiscencia de la concepción peirceana de la filosofía científica en el cuadro que presenta Quine de la epistemología, no como una disciplina separada, a priori, sino como parte integral de nuestra red total de creencias sobre el mundo, que "se continúan con la ciencia". Pero también aquí la postura de Quine resulta equívoca. Usa el término "ciencia" en forma ambigua: a veces en sentido amplio, para referirse a nuestro supuesto conocimiento empírico en general, a veces en sentido estricto, para referirse a las ciencias de manera específica y, además, manifiesta reservas, tanto de tipo skinnerianas como extensionistas, sobre el concepto de creencia. De este modo, el cuadro peirceano queda confundido, en ocasiones dentro de un cientificismo reformista en el que la epistemología se "asimila a la psicología empírica" (1981, p. 72) y en otras, incluso, dentro de un cientificismo revolucionario que sostiene que las cuestiones epistemológicas son ilegítimas y que deben ser abandonadas a favor de cuestiones psicológicas legítimas.

Hace aproximadamente veinticinco años, apareció un artículo de Ernest Gellner sobre Quine en Times Literary Supplement con el título de "The Last Pragmatist". En la medida en que se trataba de una predicción, resultó falsa. Además del pequeño ejército de editores y estudiosos del pragmatismo clásico, y además del nutrido ejército de semiólogos que siguen la nueva disciplina fundada por Peirce, cierto número de filósofos han encontrado que la tradición pragmática clásica constituye una vena rica en ideas filosóficas.

Nos viene a la mente la bella analogía que hizo Papini del pragmatismo como un gran hotel donde, en cada cuarto, hay un filósofo trabajando, cada uno de diferente manera y sobre diferente tema, pero al que todos llegan a través del mismo corredor principal: Richard Bernstein revisando la tradición pragmática clásica en busca de una reconciliación entre las partes "analítica" y "continental" actualmente en guerra; Hilary Putnam uniendo los temas abordados por James y Wittgenstein; Nicholas Rescher desarrollando su idealismo conceptual; Joseph Margolis trabajando en sus filosofías antifundacionalistas de la ciencia y la historia; Susan Haack desarrollando su crítica del sentido común en la epistemología y la filosofía de la ciencia. Además, la influencia del pragmatismo clásico todavía se siente fuera de Estados Unidos, en la obra de Jurgen Habermas, Karl-Otto Apel, Hans Joas, Umberto Eco, Gerard Deledalle, et al.; fuera de la filosofía, sobre todo en la teoría triádica transaccional de la lectura de Louise Rosenblatt, influida por Peirce y Dewey; y fuera de los círculos académicos, donde destaca el enfoque peirceano con que Jonathan Rauch aborda los temas de la libertad de pensamiento y de expresión. 
Pero cuando se habla de un resurgimiento contemporáneo del pragmatismo, es mucho más probable que se tenga en mente los neopragmatismos radicales que están ahora de moda en filosofía y, en creciente medida, también en otras disciplinas. Se podría pensar que los desenfrenados corsarios del mar de la ciencia y los desenfrenados corsarios del mar de la literatura tienen poco en común, pero los dos estilos de neopragmatismo, aunque muy diferentes en tono y temperamento, son curiosamente semejantes en su hostilidad hacia la idea o la importancia de la verdad y en su tono antifilosófico e incluso antiintelectual.

Paul Churchland es un entusiasta del estilo más científico, más revolucionario y menos peirceano del naturalismo de Quine. Es un materialista eliminacionista que cree que, como no es probable que se produza una reducción uniforme de las creencias, deseos, etc., a los estados neurofisiológicos del cerebro o del sistema nervioso central, la "psicología folclórica" - es decir, nuestras explicaciones corrientes del comportamiento de las personas por referencia a sus creencias, deseos, etc.- es falsa, y su ontología, mítica. La actividad cognitiva humana no implica creencias, deseos, representaciones, sino que sólo difiere en grado de complejidad de la de criaturas más humildes, como los nudibranquiados. Imaginando anhelantemente un día en que las bibliotecas estarán llenas, no de libros, sino de grabaciones de casos ejemplares de actividad neurofisiológica, Churchland concluye que la verdad no es el objetivo de la investigación, y que incluso la idea de verdad puede no tener sentido.

En cierto momento también Stich había insistido, aunque por razones diferentes, en que dejáramos de lado la psicología folclórica y su ontología de estados intencionales. Ahora, no obstante, reconoce que, después de todo, las personas sí tienen creencias, y creer en algo es, según lo entiende este autor, como tener un enunciado en la cabeza dentro de una caja rotulada "Creencias". Señalando que a veces una persona está en mejor posición con una creencia verdadera que con una falsa, Stich concluye que valorar la verdad contenida en nuestras creencias es un acto "profundamente conservador", una especie de superstición.

Antes de que Churchland abordara el tema, Rorty (junto con Feyerabend) había defendido el materialismo eliminacionista. Y últimamente se ha abocado a recordarnos, como Churchland, la continuidad entre la cognición humana y el quehacer cognitivo de los calamares, los nudibranquiados y demás, los cuales no se hacen ninguna representación del mundo en la cabeza (o en lo que sea). Caracterizando al pragmatismo como un "antirrepresentacionismo" (1990, p. 1), Rorty repudia la idea de la creencia como representación y también la idea de la verdad como exactitud de la representación. 
De aquí algunos de los temas recurrentes en el variable caleidoscopio de los escritos de Rorty: que los problemas metafísicos y epistemológicos que ocupan el tradicional centro de la filosofía son equívocos, pues los conceptos de verdad y creencia justificada tienen mucho menos base de lo que habitualmente han supuesto los filósofos; que la ciencia sólo es parte de la conversación de la cultura occidental, y la alta estima en que nuestra cultura tiene a lo científico no encuentra justificación en ninguna distinción epistémica objetiva y, en consecuencia, que, en vez de aspirar a volver científica a la filosofía, deberíamos transformarla en un género literario.

Según Rorty, hay dos concepciones de la verdad: el "uso casero y trillado" de la verdad como consenso, "lo que se puede defender de todos los interesados", y el "uso específicamente 'filosófico', la verdad como representación exacta, como correspondencia (1979, pp. 308-309). Sin embargo, Rorty cree que la concepción "filosófica" es inútil; llamar verdadero a un enunciado no es más que rendirle un homenaje metafísico en tanto enunciado con el que estamos de acuerdo.

Dada su actitud con respecto a la verdad, no es sorprendente que Rorty reinterprete la investigación —el intento por descubrir la verdad, por hallar de qué manera son las cosas realmente-como nada más que una especie de negociación, un intento por llegar a un acuerdo. Tampoco resulta sorprendente que separe el concepto de creencia justificada de sus conexiones con la evidencia o con la indicación de verdad, y lo reinterprete como puramente contextual, conversacional. Justificar una creencia equivale a justificarla para un público u otro, defenderla de las objeciones conversacionales, en concordancia con nuestras prácticas epistémicas.

Dadas sus opiniones de la verdad, la investigación y la justificación, a nadie asombrará ver que, caracterizándose a sí mismo como kuhniano del ala izquierda, uno de los "nuevos revoltosos" que consideran la idea misma del método científico como un síntoma de cientificismo, Rorty sostiene que "lo único ejemplar de la ciencia es que constituye un modelo de solidaridad humana" (1987, p. 46).

Y, dada su actitud hacia la ciencia, tampoco asombrará a nadie el hecho de que desapruebe la aspiración de volver más científica a la filosofía y de que, en cambio, mire hacia una alianza con la literatura. La filosofía "edificante" con "f" minúscula que Rorty propone no se dedicará a argumentar, como lo ha hecho la Filosofía tradicional, con "F" mayúscula, sino a volver a describir las cosas en forma imaginativa y metafórica. A primera vista parece incomprensible que Rorty afirme también que su filosofía edificante estará "al servicio de la política democrática" (1989, p. 196). Pero cuando exhorta a "ascender [...] a la política cultural" los tradicionales intereses metafísicos y epistemológicos (1998, p. 57), uno advierte cómo se establece 
la conexión: centrándose — de acuerdo con la moda actual en los estudios literarios- en los aspectos políticos de la literatura.

A Churchland no le preocupa la historia del pragmatismo. Stich hace referencia a James, pero el único y breve pasaje que cita para demostrar que éste coincide con él en que la verdad no es ni intrínseca ni instrumentalmente valiosa está mutilada, y la interpretación que Stich le da es tan tendenciosa que nos recuerda las quejas de James contra los críticos que "insisten en dar la interpretación más tonta posible" a las palabras de los pragmatistas. Pues, sin las expurgaciones, el pasaje comienza con la observación de que la verdad es una especie de bien, el bien bajo la forma de creencia, y pasa entonces a argumentar que las creencias verdaderas son "útiles en las luchas prácticas de la vida" (James, 1907, pp. 42-43; citado parcialmente por Stich en 1990, p. 160).

Lo que Rorty llama pragmatismo está — poniéndolo en términos moderados- muy alejado de Peirce. No hace falta más que recordar que éste fue el fundador de la teoría de la representación, comparar la insistencia de Peirce en la importancia de asumir una actitud científica, de la preocupación por la verdad, con el desdén de Rorty hacia los filósofos que creen que están buscando la verdad como "mojigatos encantadoramente pasados de moda" (1991, p. 86), o contraponer la concepción que Rorty tiene de la filosofía en tanto "forma de sostener la conversación de la cultura occidental" a la desaprobación de Peirce hacia esos diletantes a quienes les agrada tanto argumentar y dar vueltas a una cuestión que acogerían una solución auténtica con "disgusto mal disimulado" (5.396). Al leer las quejas de Rorty con respecto a la fragmentación lógica de la filosofía analítica, uno recuerda el comentario de Peirce de que "el señor Schiller y los pragmatistas de hoy" parecen abrigar "un iracundo odio hacia la lógica estricta, e incluso cierta disposición a calificar cualquier pensamiento exacto que interfiera con sus doctrinas de puras patrañas" (6.485).

Pero "los movimientos revolucionarios de una disciplina intelectual", observa Rorty, "exigen una historia revisionista de esa disciplina" (1982, p. 211). Hasta qué punto exactamente está dispuesto a ser revisionista se pone de manifiesto en este jovial comentario: "como insisto en tratar a Davidson como el más radical de los pragmatistas estadounidenses, conviene a mi propósito definir el pragmatismo en tanto algo que Davidson aprueba" (1997, p. 149). Rorty no tiene empacho en sacar sencillamente a Peirce del retrato familiar de los pragmatistas, desdeñándolo como "sólo otro frustrado maníaco de las tríadas" (1992, p. 93), cuyo único aporte al pragmatismo fue darle su nombre (1982, p. 211).

Las cosas no resultan tan simples con respecto a James y Dewey, a quienes no es cuestión, para Rorty, de sacarlos del retrato familiar, sino de retocarles 
la nariz o la barbilla por un lado, una ceja por el otro, o incluso agregarles una distintiva marca de nacimiento, para exagerar su parecido con él mismo. Por ejemplo, cuando Rorty escribe que "nosotros, los pragmatistas" pensamos que la verdad no es "la clase de cosa de la que uno espera tener una teoría interesante" (1982, p. xiii), se advierte un débil eco de la insistencia de James en que nos concentremos en las verdades concretas más que en la verdad abstracta; cuando dice que, una vez que incluimos los deseos humanos en el criterio de verdad, nos hemos convertido en pragmatistas, uno recuerda las luchas, no muy afortunadas, de James por desenmarañar el pragmatismo de la voluntad de creer; cuando propone asimilar la filosofía a la literatura, viene a la mente el reconocimiento de James de la sabiduría moral que puede transmitir una novela o una obra de teatro.

James había intentado, como Peirce y Dewey, alejarse de la teoría representativa de la percepción y, como Peirce y Dewey, mejorar la idea de la verdad como correspondencia o copia, reconociendo que no somos receptores pasivos, sino investigadores activos. Pero esto difícilmente califica como "antirrepresentacionalismo", en el sentido que es crucial para el neopragmatismo al burlesco estilo de Rorty, pues el "conjunto ideal de formulaciones" de James, como la representación última de Peirce, la opinión final, se refiere indudablemente a algo semejante a un conjunto de proposiciones.

Quizá una de las fuentes de la idea que Rorty se hizo del pragmatismo como "antirrepresentacionalismo" es la esperanza de James de que una dirección afortunada, y la esperanza de Dewey de que un éxito deliberado, pudieran sustituir la exactitud de la representación como criterio de una investigación bien realizada. Pero el repudio de Rorty a la epistemología es mucho más radical que la crítica de Dewey a la teoría del espectador, pues, al contrario de Rorty, lejos de abandonar la teoría de la investigación, Dewey la sigue a su manera característicamente instrumentalista.

Los temas se confunden en la descripción de Rorty de su postura antiepistemológica como un repudio al fundacionalismo, porque el "fundacionalismo" es ambiguo: puede referirse a una teoría de justificación epistémica que exige justificar las creencias básicas con la experiencia a fin de que sirvan como fundamento de todas las otras creencias justificadas, o a la idea de la epistemología como algo que proporciona los fundamentos a priori de la ciencia, o a la idea de que los criterios para determinar si una investigación está mejor o peor realizada, si las creencias están más o menos justificadas, son criterios objetivos, fundados en la relación entre evidencia y verdad. Dewey (como Peirce y James) es antifundacionalista en esas dos primeras acepciones, pero no en la tercera, que es esencial para el neopragmatismo al estilo de Rorty. 
Y la concepción de este último acerca de la filosofía como edificante es mucho más radical que el renacimiento de la filosofía de Dewey como amor a la sabiduría, en tanto ejercicio de la imaginación moral. Como indudablemente lo habría advertido Dewey, el escepticismo de Rorty con respecto a la verdad, la evidencia, la investigación y demás no sólo debilita a la filosofía tradicional (tal como lo pretende), sino también a la filosofía supuestamente edificante con que que Rorty espera reemplazarla. Rorty sigue usando los términos "verdad", "investigación", "justificación", etc. Pero al despojar a estos conceptos de todo lo que los arraiga en el mundo, reduciéndolos a lo puramente conversacional, debilita al mismo tiempo la esperanza de descubrir lo que es verdaderamente para el bien de la sociedad y la posibilidad de aprender de las verdades de la literatura.

Schiller es inexcusablemente relativista, mientras que Rorty se esfuerza por negar la acusación. Y de hecho, dadas sus frecuentes referencias a "nuestras prácticas conversacionales", al "sostenimiento de la conversación de la cultura occidental", quizá se clasifica mejor como tribalista que como relativista. No obstante, de los viejos pragmatistas, es Schiller a quien Rorty se parece más.

Puesto que el estilo neopragmático de Rorty ha sido acogido calurosamente por algunos estudiosos literarios, el mensaje del pragmatismo clásico ha sufrido, como consecuencia, una mayor distorsión. Es irónico, porque en 1905, al introducir su neologismo "pragmaticismo", con la esperanza manifiesta de que fuera "lo suficientemente feo para que esté a salvo de los secuestradores", Peirce había observado que la "palabra 'pragmatismo' empieza a aparecer de tanto en tanto en las publicaciones literarias, donde se abusa de ella en la despiadada forma en que deben esperar las palabras cuando caen en las garras de la literatura". El abuso continúa. Louis Menand escribe que los pragmatistas sostienen que "toda la fuerza de la explicación filosófica de una cosa [...] radica en las publicitadas [sic] consecuencias de creerla" (1997, pp. xii-xiii); uno teme que el pragmatismo vulgar esté evolucionando hacia un "rortyismo" vulgar.

Al leer los escritos reunidos por Mitchell bajo el título de Against Theory: Literary Studies and the New Pragmatism, se tiene la impresión de que el pragmatismo comenzó en 1979, con la publicación de Philosophy and the Mirror of Nature de Rorty, y que los pensadores pragmatistas más importantes, aparte de Rorty, son investigadores literarios como Stanley Fish, Steven Knapp y Walter Benn Michaels, et al. Como lo sugiere el título de Mitchell, estos neo-neopragmatistas literarios tienden a oponerse vehementemente a la teoría, vale decir, se oponen vehementemente a las teorías de la interpretación literaria, como es el caso de Derrida, de Man o sus numerosos 
admiradores. Parecen, no obstante, conjuntar una plausible resistencia a la idea de que es imposible leer un texto literario sin desplegar una amplísima teoría interpretativa, con una implausible negación de que sea posible alguna teoría de la interpretación, implausible y desconcertantemente reñida no sólo con el pragmatismo semiótico de Peirce, sino también con la propia tesis de Knapp y Benn Michaels de que el significado no es sino la intención del autor.

Oliver Wendell Holmes, participante del Club Metafísico de Cambridge, había señalado en "The Path of the Law", que "tenemos muy poca teoría en derecho, y no demasiada" (1897, p. 166). Pero cuando el investigador legal Richard Posner se alía con el [neo-neo]pragmatismo legal, lo hace por oposición al llamamiento de Ronald Dworkin a la teoría, vale decir, a la teoría de la interpretación legal. También en este caso parece que empiezan a conjuntarse dos clases de cuestiones: una plausible resistencia a la idea de que es imposible que un juez realice una interpretación judicial sin desplegar una amplísima teoría interpretativa y una implausible negación de que sea posible alguna teoría de la interpretación legal. Es cierto que Posner afirma que "la ley necesita más del espíritu científico —el falibilismo, [...] el respeto por el hecho", pero más adelante, en la misma página, agrega que el pragmatismo sostiene que "no hay verdad en el mundo" (1990, p. 432). Es difícil saber qué pensar.

Se trata nuevamente de una "confusión peor que la de Babel", y el limo todavía no se ha asentado en el fondo, como en 1907 predijo James que pronto sucedería. Por el contrario, el mensaje pragmático de Peirce ha sido gradualmente modificado y finalmente transmutado para convertirlo en el mensaje, en esencia opuesto, de los pragmatismos vulgares contemporáneos. Es fácil quedarse atrapado en la cuestión de cuáles son las variantes que califican como pragmatismo auténtico; pero es mejor —-potencialmente más fructuoso y apropiadamente progresista- preguntarse más bien qué podemos aprender de la vieja tradición pragmática y del naufragio intelectual de la nueva.

BIBLIOGRAFÍA

Alexander, Thomas M. y Larry A. Hickman (eds.), 1998, The Essential Dewey: vol. I: Pragmatism, Education, Democracy, Indiana University Press, Bloomington, Indiana.

Bernstein, Richard, 1988, "Pragmatism, Pluralism, and the Healing of Wounds", discurso pronunciado en el encuentro de la División Este de la Asociación 
Filosófica Estadounidense; publicado como apéndice de The New Constellation: The Ethical-Political Horizons of Modernity/Postmodernity, MIT Press, Cambridge, Massachusetts, 1991, pp. 323-340, y reproducido en Menand 1997, pp. 382-400. Bird, Graham (ed.), 1995, William James: Selected Writings, edición popular, J.M. Dent, Londres y Charles E. Tuttle, Vermont.

Clifford, William Kingdon, 1877, "The Ethics of Belief", en The Ethics of Belief and Other Essays, Watts and Co., Londres, 1947, pp. 70-96.

Churchland, Paul M., 1989, A Neurocomputational Perspective: The Nature of Mind and the Structure of Science, Bradford Books, MIT Press, Cambridge, Massachusetts.

Dewey, John, 1909, Moral Principles in Education; incluye "The Moral Training Given by the School Community", reproducido en Alexander y Hickman 1998, pp. 246249. Las referencias a las páginas en el texto correponden a Alexander y Hickman.

- 1910, The Influence of Darwin on Philosophy, Henry Holt, Nueva York.

_ - 1916, "The Pragmatism of Peirce", en Middle Works, Jo Ann Boydston (ed.), Southern Illinois University Press, Carbondale, Illinois, vol. 10, 1988, pp. 71-78.

—-, 1916a, Democracy and Education, MacMillan, Nueva York.

__, 1919, "Philosophy and Democracy", en Alexander y Hickman, 1998, pp. 7178.

— , 1927, The Public and Its Problems; incluye "Search for the Great Community", reproducido en Alexander y Hickman, 1998, pp. 293-307; las referencias a las páginas en el texto corresponden a Alexander y Hickman.

—_, 1929, The Quest for Certainty, Putnam, Nueva York, 1960.

—_, 1931, "Body and Mind", Philosophy and Civilization, Nueva York.

__ 1937, "Democracy is Radical", Common Sense, 6, pp. 10-11, reproducido en Alexander y Hickman, 1998, pp. 337-339; las referencias a las páginas en el texto corresponden a Alexander y Hickman.

— 1938, Logic, The Theory of Inquiry, Henry Holt, Nueva York.

Dykhuizen, George, 1973, The Life and Mind of John Dewey, Southern Illinois University Press, Carbondale, Illinois.

Haack, Susan, 1993, Evidence and Inquiry: Towards Reconstruction in Epistemology, Blackwell, Oxford.

__, 1995, "Puzzling Out Science", Academic Questions, pp. 25-31; reproducido en Haack 1998, pp. 90-103.

_ 1996, "Reflections of a Critical-Commonsensist", Transactions of the Charles $S$. Peirce Society, XXXIII, 3, pp. 359-373.

_ _ 1996a. "Science or Social? —Yes and No", en Jack Nelson y Lynn Hankinson Nelson (eds.), Feminism, Science, and Philosophy of Science, Kluwer, Dordrecht, Holanda, pp. 79-93; reproducido en Haack 1998, pp. 104-122.

__ 1998, Manifesto of a Passionate Moderate: Unfashionable Essays, University of Chicago Press, Chicago, Illinois.

Habermas, Jurgen, 1981, Theorie des Kommunikativen Handelns, Suhrkamp, Fráncfort del Meno.

Holmes, Oliver Wendell, 1897, "The Path of the Law", Harvard Law Review, 10, pp. 457-78, reproducido en Holmes, Collected Legal Papers, Harcourt, Brace 
and Howe, Nueva York, 1920, pp. 167-202, y en Menand 1997, pp. 145-169; las referencias a las páginas en el texto corresponden a Menand 1997.

James, William, 1890, Principles of Psychology, 3 vols., Frederick H. Burkhardt, Bowers y Skrupskelis (eds.), Harvard University Press, Cambridge, Massachusetts, 1981. La referencia a la página en el texto corresponde a un resumen, "Habit", reproducido en Menand 1997, pp. 60-68.

__ 1891, "The Moral Philosopher and the Moral Life", International Journal of Ethics, reproducido en James 1897 y en Bird 1995, pp. 298-319; las referencias a las páginas en el texto corresponden a Bird.

—, 1897, The Will to Believe and Other Essays in Popular Philosophy, Dover, Nueva York, 1956; Burkhardt, Bowers y Skrupskelis (eds.), Harvard University Press, Cambridge, Massachusetts, 1979. Las referencias a las páginas en el texto corresponden a la edición de Dover.

__, 1899, Talks to Teachers; incluye "On a Certain Blindness in Human Beings", también reproducido en Bird 1995, pp. 320-360.

—, 1902, The Varieties of Religious Experience, Burkhardt, Bowers y Skrupskelis (eds.), Harvard University Press, Cambridge, Massachusetts, 1985.

— 1903 , "The Ph. D. Octopus", Harvard Monthly; reproducido en William James, Writings 1902-1910, Library of America, Nueva York, 1987, pp. 1111-1118.

—_, 1904, “Does Consciuosness Exist?”, reproducido en James 1912 y en Bird 1995, pp. 100-116; las referencias a las páginas en el texto corresponden a Bird 1995.

—- 1907, Pragmatism: A New Name for Some Old Ways of Thinking, Burkhardt, Bowers y Skrupskelis (eds.), Harvard University Press, Cambridge, Massachusetts, 1975.

—_, 1907a, "An Interview: Pragmatism —What It Is", New York Times, 3 de noviembre de 1907, realizada por Edwin Bjorkman y reproducida en Thayer 1970, pp. 130-134; las referencias a las páginas en el texto corresponden a Thayer. La última sección de la entrevista lleva el encabezado "Confusion Worse Than Babel".

—, 1909, The Meaning of Truth: A Sequel to "Pragmatism", Burkhardt, Bowers y Skrupskelis (eds.), Harvard University Press, Cambridge, Massachusetts, 1975.

—, 1909a, A Pluralistic Universe: Hibbert Lectures at Manchester College on the Present Situation in Philosophy, Longmans, Green, Nueva York; Burkhardt, Bowers y Skrupskelis (eds.), Harvard University Press, Cambridge, Massachusetts, 1977.

—_, 1912, Essays in Radical Empiricism, Richard Bernstein (ed.), Dutton, Nueva York, 1971; Burkhardt, Bowers y Skrupskelis (eds.), Harvard University Press, Cambridge, Massachusetts, 1977.

Joas, Hans, 1993, Pragmatism and Social Theory, University of Chicago Press, Chicago.

Kloesel, Christian y Nathan Houser (eds.), 1992, The Essential Peirce, vol. 1, Indiana University Press, Indianápolis y Bloomington. (El volumen 2, editado por el Proyecto de Ediciones Peirce, fue publicado por Indiana University Press en 1998.) 
Knapp, Steven y Walter Benn Michaels, 1995, "Against Theory", en Mitchell, W.J.T. (ed.), 1995, pp. 11-18, 24-30.

Ladd-Franklin, Christine, 1916, "Charles Sanders Peirce at the Johns Hopkins", Peirce Commemorative Issue of the Journal of Philosophy, Psychology, and Scientific Methods, XII.

Lewis, C.I., 1923, "A pragmatic Conception of the A Priori", Journal of Philosophy, XX, pp. 169-177; reproducido en Thayer, 1970, pp. 367-374; las referencias a las páginas en el texto corresponden a Thayer.

— 1929, Mind and the World Order, Charles Scribner's Sons, Nueva York.

— 1946, An Analysis of Knowledge and Valuation Open Court, La Salle, Illinois.

Lovejoy, Arthur C., 1908, "The Thirteen Pragmatisms", Journal of Philosophy, 5.8, pp. 36-39; reproducido en Amelie Rorty, 1966, pp. 339-341.

Margolis, J., 1986, Pragmatism Without Foundations, Blackwell, Oxford.

— 1993, The Flux of History and the Flux of Science, University of California Press, Berkeley y Los Ángeles.

Mead, George Herbert, 1910, "Social Consciousness and the Consciousness of Meaning", The Psychological Bulletin, VII, pp. 397-405; reproducido en Reck 1964, pp. 123-133, y en Thayer 1970, 341-350.

—_, "The Social Self", 1913, The Journal of Philosophy, Psychology, and Scientific Methods, X, pp. 374-380; reproducido en Reck 1964, pp. 142-149, y en Thayer 1970, pp. 351-358.

—_, 1934, Mind, Self and Society (notas para sus conferencias a los estudiantes), Charles W. Morris (ed.), University of Chicago Press, Chicago, Illinois, 1962.

Menand, Louis (ed.), 1997, Pragmatism: A Reader, Vintage Books, Random House, Nueva York.

Mitchell, W.J.T. (ed.), 1985, Against Theory, University of Chicago Press, Chicago, Illinois.

Moore, G.E., 1907-1908, “William James's 'Pragmatism'”, Proceedings of the Aristotelian Society, N.S. 8; reproducido en Philosophical Studies, Routledge and Kegan Paul, Londres, 1922, pp. 123-129, y en Amelie Rorty, 1966, pp. 328-338.

Mounce, H.O., 1997, The Two Pragmatisms: From Peirce to Rorty, Routledge, Londres. Peirce, Charles Sanders, 1931-1958, CP, Collected Papers, Charles Hartshorne, Paul Weiss (eds.) (volúmenes 1-6), y Arthur Burks (ed.) (volúmenes 7 y 8), Harvard University Press, Cambridge, Massachusetts; las referencias en el texto corresponden al número de volumen y de parágrafo.

—_, 1900, Reseña de Clark University, 1889-1899: Decennial Celebration, Science, pp. 620-622; reproducido en Wiener, P. P. (ed.), Charles S. Peirce: Selected Writings, Doubleday, Nueva York, 1966, las referencias a las páginas corresponden a Weiner.

—, 1904, "A Definition of Pragmatism", tomado del borrador de una reseña de A Treatise on Cosmology de Herbert Nichols (1904), en James Hoopes, Peirce on Signs: Writings on Semiotic by Charles Sanders Peirce, University of North Carolina Press, Chapel Hill, 1991, pp. 246-248, y reproducido en Menand 1997, pp. 5658; las referencias a las páginas en el texto corresponden a Menand. 
Posner, Richard, 1990, "A Pragmatist Manifesto", tomado de The Problems of Jurisprudence, Harvard University Press, Cambridge, Massachusetts, pp. 454-469; reproducido en Menand 1997, pp. 418-435; las referencias a las páginas en el texto corresponden a Menand.

Quine, W.V.O., 1933-1935, Reseña de Isis de Peirce, 19, pp. 220-229; 22, pp. 285297, 551-553.

—_, 1951, "Two Dogmas of Empiricism”, Philosophical Review, reproducido en From a Logical Point of View, Harvard University Press, Cambridge, Massachusetts, 1953 y reeditado por Harper Torchbooks, Nueva York, 1963, pp. 20-46; las referencias a las páginas en el texto corresponden a la edición de Harper Torchbooks.

—, 1969, Ontological Relativity and Other Essays, Columbia University Press, Nueva York.

—_, 1969a, "Natural Kinds", en Quine 1969, pp. 114-138.

—_, 1969b, "Epistemology Naturalized”, en Quine 1969, pp. 69-90.

—_, 1981, "The Pragmatists' Place in Empiricism", en Robert J. Mulvaney y Philip M. Zeltner (eds.), Pragmatism: Its Sources and Prospects, University of South Carolina Press, Columbia, Carolina del Sur.

__, 1981a, "Five Milestones of Empiricism", en Theories and Things, Belknap Press of Harvard University Press, Cambridge, Massachusetts, pp. 1-23.

— 1985 , The Time of My Life, Bradford Books, MIT Press, Cambridge, Massachusetts.

Ramsey, F.P., 1927, "Facts and Propositions", Aristotelian Society, Supplementary Volume, VII, pp. 153-170; reproducido en The Foundations of Mathematics, Richard Braithwaite (ed.), Routledge and Kegan Paul, Londres, 1931.

Rauch, Jonathan, 1993, Kindly Inquisitors: The New Attacks on Free Thought, University of Chicago Press, Chicago, Illinois.

Reck, Andrew J. (ed.), 1964, Selected Writings of George Herbert Mead, Bobbs-Merrill, Nueva York.

Rescher, Nicholas, 1992, A System of Pragmatic Idealism, 3 vols., Princeton University Press, Princeton, Nueva Jersey.

Rorty, Amelie (ed.), 1966, Pragmatic Philosophy, Anchor Books, Doubleday, Nueva York.

— 1979 , Philosophy and the Mirror of Nature, Princeton University Press, Princeton, Nueva Jersey.

— 1982, Consequences of Pragmatism, Harvester, Hassocks, Sussex.

__, 1987, "Science as Solidarity", en John S. Nelson, Allan Megill y Donald M. McCloskey (eds.), The Rhetoric of the Human Sciences, University of Wisconsin Press, Madison, Wisconsin, pp. 38-52.

—, 1989, Contingency, Irony and Solidarity, Cambridge University Press, Cambridge.

— Westview, Boulder, Colorado, pp. 1-6.

—, 1991, Objetivity, Relativism and Truth, Cambridge University Press, Cambridge.

—, $1991 \mathrm{a}$, Essays on Heidegger and Others, Cambridge University Press, Cambridge. 
_ 1992 , “The Pragmatism's Progress", en Stefan Collini (ed.), Interpretation and Over-Interpretation, Cambridge University Press, pp. 89-108.

_, 1997 , "Realism, Anti-Realism, and Pragmatism: Comments on Alston, Chisholm, Harman, and Searle", en Christopher Kalp (ed.), Realism/Antirrealism and Epistemology, Rowman and Littlefield, Maryland, pp. 149-172.

— 1998 , Truth and Progress, Cambridge University Press, Cambridge.

Rosenblatt, Louise, 1978, The Reader, The Text, The Poem: The Transactional Theory of the Literary Work, Southern Illinois University Press, Carbondale, Illinois.

— 1994, "The transactional Theory of Reading and Writing", en Theoretical Models of Reading, R.B. Ruddell, M.R. Ruddell y H. Singer (eds.), International Reading Association, Newark, Delaware, pp. 1057-1092.

Royce, Josiah, 1908, "The Problem of Truth in the Light of Recent Discussion", Proceedings of the International Congress of Philosophy of Heidelberg; reproducido en Royce, William James and Other Essays on the Philosophy of Life, MacMillan, Nueva York, 1911, y en D.S. Robinson (ed.), Royce's Logical Essays, Wm. C. Brown Company, Dubuque, Iowa, 1951. La referencia a las páginas en el texto corresponde a William James and Other Essays.

Russell, Bertrand, 1910, “Transatlantic 'Truth' ", Albany Review, reproducido bajo el título "William James's Conception of Truth", en Philosophical Essays, Longman's, Green, Nueva York, pp. 135-138, 144-149, y en Amelie Rorty, 1966, pp. 310315.

—, 1928, Sceptical Essays, W.W. Norton, Nueva York, y Allen and Unwin, Londres. Schiller, F.C.S., 1907, Studies in Humanism, MacMillan, Londres.

Stich, Stephen P., 1990, The Fragmentation of Reason: Preface to a Pragmatic Theory of Cognitive Evaluation, Bradford Books, MIT Press, Cambridge, Massachusetts.

Thayer, H.S. (ed.), 1970, Pragmatism: The Classical Writingsk, Mentor, Nueva York; reimpreso por Hackett, Indianápolis, Indiana, 1982.

White, Morton G., 1950, "The Analytic and the Synthetic: An Untenable Dualism", en Sidney Hook (ed.), John Dewey: Philosopher of Science and Freedom, Dial Press, Nueva York, pp. 316-330.

[Traducción: Ana Isabel Stellino]

Recibido: 7 de noviembre de 2000

Aceptado: 15 de diciembre de 2000 